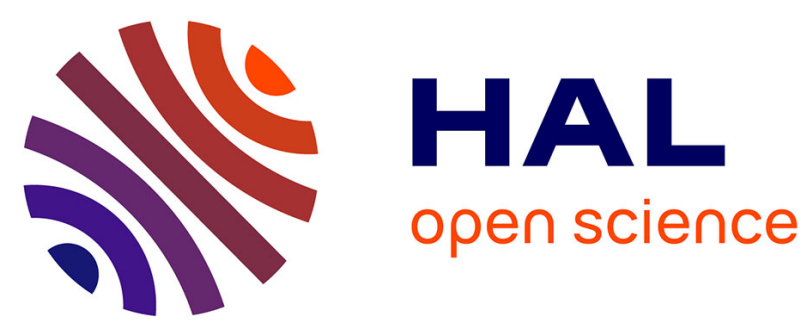

\title{
Ice volume and subglacial topography for western Canadian glaciers from mass balance fields, thinning rates, and a bed stress model
}

G. K. C. Clarke, F. Anslow, A. Jarosch, V. Radic, Brian Menounos, Tobias Bolch, Etienne Berthier

\section{To cite this version:}

G. K. C. Clarke, F. Anslow, A. Jarosch, V. Radic, Brian Menounos, et al.. Ice volume and subglacial topography for western Canadian glaciers from mass balance fields, thinning rates, and a bed stress model. Journal of Climate, 2013, 26 (12), pp.4282-4303. 10.1175/JCLI-D-12-00513.1 . hal-00846330

\section{HAL Id: hal-00846330 \\ https://hal.science/hal-00846330}

Submitted on 13 May 2014

HAL is a multi-disciplinary open access archive for the deposit and dissemination of scientific research documents, whether they are published or not. The documents may come from teaching and research institutions in France or abroad, or from public or private research centers.
L'archive ouverte pluridisciplinaire HAL, est destinée au dépôt et à la diffusion de documents scientifiques de niveau recherche, publiés ou non, émanant des établissements d'enseignement et de recherche français ou étrangers, des laboratoires publics ou privés. 


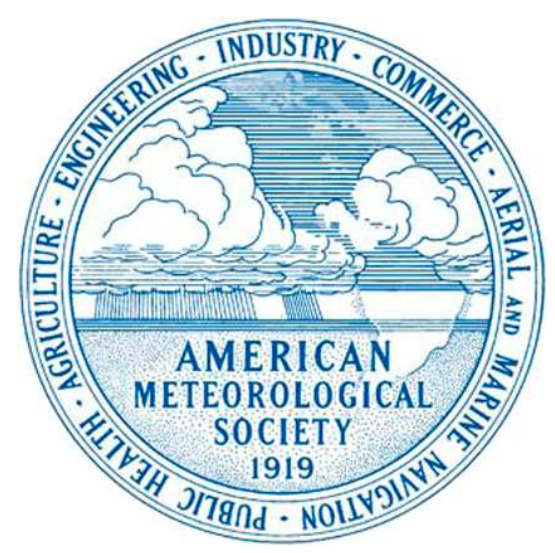

\title{
AMERICAN METEOROLOGICAL SOCIETY
}

\author{
Journal of Climate
}

\section{EARLY ONLINE RELEASE}

This is a preliminary PDF of the author-produced manuscript that has been peer-reviewed and accepted for publication. Since it is being posted so soon after acceptance, it has not yet been copyedited, formatted, or processed by AMS Publications. This preliminary version of the manuscript may be downloaded, distributed, and cited, but please be aware that there will be visual differences and possibly some content differences between this version and the final published version.

The DOI for this manuscript is doi: $10.1175 / J C L I-D-12-00513.1$

The final published version of this manuscript will replace the preliminary version at the above $\mathrm{DOI}$ once it is available.

If you would like to cite this EOR in a separate work, please use the following full citation:

Clarke, G., F. Anslow, A. Jarosch, V. Radic, B. Menounos, T. Bolch, and E. Berthier, 2012: Ice volume and subglacial topography for western Canadian glaciers from mass balance fields, thinning rates, and a bed stress model. J. Climate. doi:10.1175/JCLI-D-12-00513.1, in press. 


\title{
Ice volume and subglacial topography for
}

2 western Canadian glaciers from mass balance

s fields, thinning rates, and a bed stress model

\author{
Garry K. C. Clarke
}

Department of Earth, Ocean and Atmospheric Sciences,

University of British Columbia, Vancouver, British Columbia, Canada

FARON S. ANSLOW

Pacific Climate Impacts Consortium, University of Victoria, Victoria, British Columbia, Canada

6 Alexander H. Jarosch

Centre for Climate and Cryosphere, University of Innsbruck,

Innsbruck, Austria

VALENTINA RADić

University of British Columbia, Vancouver, British Columbia, Canada 


\section{Brian Menounos}

Natural Resources and Environmental Studies Institute, University of Northern British Columbia, Prince George, British Columbia, Canada

\section{TOBIAS BOLCH}

Department of Geography, University of Zurich, Zürich, Switzerland

and

Institut für Kartographie, Technische Universität Dresden, Dresden, Germany

Université de Toulouse-OMP/LEGOS, and Centre National de la Recherche Scientifique-LEGOS, Toulouse, France

${ }^{*}$ Corresponding author address: Garry K. C. Clarke, Earth, Ocean and Atmospheric Sciences, University of British Columbia, 6339 Stores Road, Vancouver, BC V6T 1Z4, Canada. E-mail: clarke@eos.ubc.ca 
A method is described to estimate the thickness of glacier ice using information derived from the measured ice extent, surface topography, surface mass balance, and rate of thinning or thickening of the ice column. Shear stress beneath an ice column is assumed to be simply related to ice thickness and surface slope, as for an inclined slab, but this calculation is cast as a linear optimization problem so that a smoothness regularization can be applied. Assignment of bed stress is based on the flow law for ice and a mass balance calculation but must be preceded by delineation of the ice flow drainage basin. Validation of the method is accomplished by comparing thickness estimates to the known thickness generated by a numerical ice dynamics model. Once validated, the method is used to estimate the subglacial topography for all glaciers in western Canada that lie south of $60^{\circ} \mathrm{N}$. Adding the present ice volume of each glacier gives the estimated total volume as $2320 \mathrm{~km}^{3}$, equivalent to $5.8 \mathrm{~mm}$ of sea-level rise. Taking the glaciated area as $26590 \mathrm{~km}^{2}$ gives the average glacier thickness as $87.2 \mathrm{~m}$. A detailed error analysis indicates that systematic errors are likely to increase the estimated sea-level rise and when random errors are included the combined result is $6.3 \pm 0.6 \mathrm{~mm}$ or, expressed as ice volume, $2530 \pm 220 \mathrm{~km}^{3}$.

\section{Introduction}

The projected shrinkage of Earth's glaciers and ice caps will raise sea level (e.g., Radić and Hock 2011) and affect the water cycle over large areas of Asia, Europe, and the Americas (e.g., Kaser et al. 2010). Improved knowledge of the rate and magnitude of these changes, on a region-by-region basis, is essential and ice flow modeling provides one method to quantify these changes and make projections. Before such models can be used it is necessary to obtain a digital elevation model (DEM) of the underlying subglacial topography. For Earth's $\sim 200000$ glaciers this is problematic because few have been geophysically mapped and at present no satellite remote sensing instrument can image subglacial topography. 
Recent work on ice thickness estimation includes methods that are predominantly geometrical, such as that of Clarke et al. (2009) which is based on artificial neural networks, and those that incorporate assumptions from glacier physics (e.g., Farinotti 2010; Farinotti et al. 2009a; Huss and Farinotti 2012; Linsbauer et al. 2009, 2012; Li et al. 2011; Marshall et al. 2011; Morlighem et al. 2011; Paul and Linsbauer 2011). The attraction of the former approach is its parsimony, but it is cumbersome to implement and can lead to subglacial topography that diverges from the true topography - a concern when the estimated bed topography is to be used as a boundary condition for ice dynamics modeling. For this reason physics-rooted approaches are favored.

The aims of the present contribution are to develop a physically-based method for ice thickness estimation, to validate the method by applying it to artificial datasets generated by a numerical ice dynamics model, and to use the method to estimate the subglacial topography of glaciers in the mountainous regions of British Columbia (BC) and Alberta (AB) in western Canada. The 2005 AD ice volume and its sea-level equivalent are then calculated by summing calculated ice volume for individual glaciers. A recent inventory of glaciers in the study area indicated that in 2005 the number of glaciers was $\sim 17600$ and the area of glacierized terrain was $\sim 26700 \mathrm{~km}^{2}$ (Bolch et al. 2010). For reference, in the 1970 s some 5050 "perennial surface ice bodies" with a combined area of $2909 \mathrm{~km}^{2}$ were identified in the European Alps (Haeberli and Hoelzle 1995) and for the Swiss Alps alone there are 1483 glaciers with a total area of $\sim 1063 \mathrm{~km}^{2}$ (Farinotti et al. 2009b). Our point in making these comparisons is that the $\mathrm{BC}-\mathrm{AB}$ dataset is too large to be dissected on a glacier-by-glacier basis, so any procedure for generating ice thickness estimates must heavily rely on unguided automatic computation rather than expert intervention.

Comparisons between scientific knowledge of glaciers in western North America and those in Europe also justify the departure from methods that have been successfully applied to glaciers in the Swiss Alps. The western North America study region is data poor and of the $\sim 17,600$ glaciers, few have received scientific attention, yielding only a handful of 
published ice thickness measurements (e.g., Doell 1963; Kanasewich 1963; Paterson 1970; Raymond 1971a,b; Holdsworth et al. 2006). Most of these measurements were taken decades before our study and, in most cases, the map locations and surface elevations of the sites were not tied to a conventional geodetic reference frame. Furthermore the glaciers have thinned substantially so that the surface elevation is now much lower than at the time of measurement.

Historically, methods of ice thickness estimation have used the idea that glacier ice can be approximated as an ideal plastic material so that bed stress $\tau^{*}$ corresponds to the constant plastic yield stress $\tau_{0}$ (Orowan 1949). While the implication of a well-defined yield stress is conceptually attractive it suggests that $\tau_{0}$ is a physical property of ice and invites misleading assertions such as the "yield stress of glacier ice is 1 bar". If this were truly the case then a single yield stress value could be applied to all glaciers that were sufficiently healthy to maintain the basal stress at this value. Nonetheless several authors have made good use of the plasticity idea. From a 1938 map of the ice surface topography and the assumption that $\tau^{*}=88 \mathrm{kPa}$, Nye (1952a) produced a first map of the subglacial topography of the Greenland Ice Sheet. Later, Reeh (1982) presented an elegant account of three-dimensional plasticity modeling of ice sheet form and in subsequent publications Reeh (1984) and Fisher et al. (1985) applied this to the contemporary Greenland Ice Sheet, ice caps of the Canadian Arctic islands, and the Laurentide Ice Sheet. Crucially, Reeh noted that the assignment of basal shear stress depended on "accumulation rate, basal temperature, etc." (Reeh 1984, p. 116).

Rather than assign a single bed stress for all cases, it is better to assign a single stress $\tau^{*}$ for each glacier or, more ambitiously, a spatially-varying bed stress $\tau_{i, j}^{*}$ based on factors such as the mass balance forcing and observed rate of surface elevation change. A recent approach to this problem, described in Linsbauer et al. (2009) and Paul and Linsbauer (2011), assumes 
a constant glacier-wide bed stress given by

$$
\tau^{*}= \begin{cases}0.005+1.598 \Delta Z-0.435(\Delta Z)^{2} & \Delta Z \leq 1.6 \mathrm{~km} \\ 1.5 & \Delta Z>1.6 \mathrm{~km}\end{cases}
$$

where $\Delta Z=Z_{\mathrm{H}}-Z_{\mathrm{L}}$ with $Z_{\mathrm{H}}$ being the highest elevation of the flowshed, $Z_{\mathrm{L}}$ is the lowest, and $\tau^{*}$ has units of bars (hPa). Equation 1 is empirical (Haeberli and Hoelzle 1995, Fig. 1) but clever and is based on data from the European Alps. The elevation span $\Delta Z$ is an indirect though readily observed indicator of the mass balance turnover for a particular glacier. However, there is a concern that (1) must be tuned to specific geographical settings. For this reason, we focus on estimating glacier-specific but space-varying bed stress (Section $3)$.

\section{Thickness estimation as an optimization problem}

We assume that surface topography is represented by a matrix of elevation values $S_{i, j}$ expressing the elevation map positions $\left(x_{i}, y_{j}\right)$ in a Cartesian coordinate system. The cells are assumed to be square with dimensions $\Delta x \times \Delta y$ which, for our study, are $200 \mathrm{~m} \times 200 \mathrm{~m}$ which matches the resolution of a prognostic ice flow model that we are also developing. Co-registered with this DEM is a second matrix, referred to as the ice mask, which has the properties $I_{i, j}=1$ when the ice cover is greater or equal to $50 \%$ and $I_{i, j}=0$ otherwise. Given $S_{i, j}$ and $I_{i, j}$ together with information on the mass balance forcing and the rate of surface elevation change, we estimate the ice thickness $H_{i, j}$ for the $I_{i, j}=1$ cells and, from this, produce a map of the bed topography $B_{i, j}$, where $B_{i, j}=S_{i, j}-H_{i, j}$ when $I_{i, j}=1$ and $B_{i, j}=S_{i, j}$ when $I_{i, j}=0$.

For an ice slab of uniform thickness inclined at an angle $\theta$, the relationship between 
bottom stress $\tau^{*}$ and slab thickness is

$$
h=\frac{\tau^{*}}{\rho g \sin \theta},
$$

where $\rho$ is the density and $g$ is the gravity acceleration. In the shallow ice approximation (e.g., Fowler and Larson 1978), Equation 2 is valid everywhere, and thus can be written $h_{i, j}=\tau_{i, j}^{*} / \rho g \sin \theta_{i, j}$. The vertical distance between the upper and lower boundary of the slab is given by $H_{i, j}=h_{i, j} / \cos \theta_{i, j}$ so $(2)$ gives

$$
H_{i, j}=\frac{\tau_{i, j}^{*}}{\rho g \sin \theta_{i, j} \cos \theta_{i, j}} .
$$

The obvious implication of (3) is that ice thickness $H_{i, j}$ can be estimated if the surface slope $\theta_{i, j}$ and bed stress $\tau_{i, j}^{*}$ are known. When the base is not parallel to the surface, Nye (1952b) showed that surface slope has the dominant influence on bed stress — at least for small values of slope - so we take $\theta_{i, j}$ to correspond to the glacier surface slope $\left|\nabla_{x y} S_{i, j}\right|=\tan \theta_{i, j}$, where $\nabla_{x y} S_{i, j}$ denotes the two-dimensional gradient of the surface topography at the grid point $(i, j)$. Equation 3 can therefore be written

$$
H_{i, j}=\frac{1+\left|\nabla_{x y} S_{i, j}\right|^{2}}{\left|\nabla_{x y} S_{i, j}\right|} \frac{\tau_{i, j}^{*}}{\rho g} .
$$

Solving (4) is equivalent to minimizing a cost function of the form

$$
\mathcal{J}_{0}=\sum_{I_{i, j}=1}\left[H_{i, j}-\frac{1+\left|\nabla_{x y} S_{i, j}\right|^{2}}{\left|\nabla_{x y} S_{i, j}\right|} \frac{\tau_{i, j}^{*}}{\rho g}\right]^{2},
$$

where the summation is performed over all ice-covered cells.

A second approach to estimating $H_{i, j}$ is to use Laplacian interpolation (e.g., Press et al. 2007, p. 151), which is equivalent to solving $\nabla_{x y}^{2} H_{i, j}=0$ subject to the boundary condition $H_{i, j}=0$ beyond the glacier margins. Combining the two approaches and introducing a 
spatially-varying tradeoff parameter $\chi_{i, j}$, the ice thickness estimates are obtained by minimizing the modified cost function

$$
\mathcal{J}=\sum_{I_{i, j}=1}\left\{\chi_{i, j}\left[H_{i, j}-\frac{1+\left|\nabla_{x y} S_{i, j}\right|^{2}}{\left|\nabla_{x y} S_{i, j}\right|} \frac{\tau_{i, j}^{*}}{\rho g}\right]^{2}+\left(1-\chi_{i, j}\right) \lambda^{4}\left[\nabla_{x y}^{2} H_{i, j}\right]^{2}\right\} .
$$

The factor $\lambda^{4}:=\sigma_{H}^{2} / \sigma_{\text {Lap } H}^{2}$ has been inserted to yield dimensional consistency and to ensure that the two cost terms have comparable magnitude before they are subjected to the $\chi_{i, j}$ weightings; $\sigma_{H}$ is an estimate of the standard deviation of the first square-bracketed term and $\sigma_{\mathrm{Lap} H}$ is that for the second. Hereafter we assume $\sigma_{H}=25 \mathrm{~m}$ and $\sigma_{\mathrm{Lap} H}=0.0025 \mathrm{~m}^{-1}$, so that $\lambda$ is fixed at $\lambda=100 \mathrm{~m}$, and then use $\chi_{i, j}$ to manage the tradeoff between the cost terms. For $\chi_{i, j}=1$ the thickness estimate is entirely based on the stress relation (4) and for $\chi_{i, j}=0$ the estimate is generated by Laplacian interpolation among neighboring cells.

The tradeoff parameter $\chi_{i, j}$ can be set to vary with spatial position in order to give the greatest weight to the estimator that has the most authority at a given point. For example, in the central regions of ice caps, where the surface slope is small and the stress-based estimator (3) becomes sensitive to small fluctuations in $\theta_{i, j}$, the tradeoff parameter $\chi_{i, j}$ can be set to a small value so that the thickness estimate is largely or entirely based on Laplacian interpolation.

Substituting a finite-difference approximation for $\nabla_{x y}^{2} H_{i, j}$ in (6) gives

$$
\begin{aligned}
\mathcal{J}= & \sum_{I_{i, j}=1}\left\{\chi_{i, j}\left[H_{i, j}-\frac{1+\left|\nabla_{x y} S_{i, j}\right|^{2}}{\left|\nabla_{x y} S_{i, j}\right|} \frac{\tau_{i, j}^{*}}{\rho g}\right]^{2}\right. \\
& \left.+\left(1-\chi_{i, j}\right)\left(\frac{\lambda}{\Delta x}\right)^{4}\left[H_{i-1, j}+H_{i+1, j}+H_{i, j-1}+H_{i, j+1}-4 H_{i, j}\right]^{2}\right\} .
\end{aligned}
$$

Differentiating $\mathcal{J}$ with respect to $H_{i, j}$ and setting the result to zero gives a system of equations 
that minimizes $\mathcal{J}$,

$$
\begin{aligned}
\chi_{i, j} & {\left[H_{i, j}-\frac{1+\left|\nabla_{x y} S_{i, j}\right|^{2}}{\left|\nabla_{x y} S_{i, j}\right|} \frac{\tau_{i, j}^{*}}{\rho g}\right] } \\
& -4 \alpha\left(1-\chi_{i, j}\right)\left[H_{i-1, j}+H_{i+1, j}+H_{i, j-1}+H_{i, j+1}-4 H_{i, j}\right]=0,
\end{aligned}
$$

where $\alpha:=\lambda^{4} /(\Delta x)^{4}$. Reorganizing (8) gives

$$
\begin{aligned}
& -4 \alpha\left(1-\chi_{i, j}\right) H_{i-1, j}-4 \alpha\left(1-\chi_{i, j}\right) H_{i+1, j}-4 \alpha\left(1-\chi_{i, j}\right) H_{i, j-1}-4 \alpha\left(1-\chi_{i, j}\right) H_{i, j+1} \\
& +\left[\chi_{i, j}+16 \alpha\left(1-\chi_{i, j}\right)\right] H_{i, j}=\chi_{i, j}\left[\frac{1+\left|\nabla_{x y} S_{i, j}\right|^{2}}{\left|\nabla_{x y} S_{i, j}\right|} \frac{\tau_{i, j}^{*}}{\rho g}\right],
\end{aligned}
$$

which represents a set of linear equations having the form $\mathbf{A H}=\mathbf{C}$, where $\mathbf{H}$ is a column vector formed from the unknown ice thickness values $H_{i, j}$, $\mathbf{A}$ is the matrix of coefficients, and $\mathbf{C}$ is a column vector formed from the known righthand-side terms of (9). For a large domain the coefficient matrix $\mathbf{A}$ can be huge but the matrix is sparse and the solution can be found remarkably rapidly (e.g., 420000 unknown $H_{i, j}$ values in roughly 4 hours of machine time on a desktop workstation). From test runs it was established that computing time increases linearly with problem size.

The tradeoff parameter $\chi_{i, j}$ controls the weighting that is assigned to the stress-based estimator relative to that assigned for the Laplacian interpolation estimator. First a default value $\chi_{0}$ must be assigned and this is decided by balancing the conflicting requirements of resolving changes in ice thickness while maintaining a smooth spatial pattern. By applying the inversion method to the output of a numerical ice dynamics model (for which the simulated ice thickness is perfectly known), we found that $\chi_{0}=0.40$ yields a satisfactory compromise. Where surface slopes were small we reduced $\chi_{i, j}$ in a smooth fashion, as described in Section 4. 


\section{Estimation of basal stress}

Our approach to estimating basal stress is similar to that of Farinotti et al. (2009a) and is based on automated delineation of glacier flowsheds and application of the continuity equation. The term "flowshed" has been adopted to describe a glacier flow unit that is defined by its ice catchment. In many situations there is no distinction between a glacier and a glacier flowshed, but for glaciers that share a common catchment region the boundary between individual glaciers emanating from that catchment is defined by ice drainage divides.

The principle of ice volume conservation can be expressed as

$$
\operatorname{div}_{x y} \mathbf{q}=\dot{b}-\dot{H}
$$

where $\operatorname{div}_{x y}$ denotes the two-dimensional divergence, $\mathbf{q}$ is the vertically-integrated volume flux of ice per unit width $\left(\mathrm{m}^{2} \mathrm{yr}^{-1}\right), \dot{b}$ is the ice-equivalent mass balance rate $\left(\mathrm{m} \mathrm{yr}^{-1}\right)$, and $\dot{H}$ is the rate of change of ice thickness $\left(\mathrm{m} \mathrm{yr}^{-1}\right)$. In the glacier accumulation zone the mass balance rate is positive; in the ablation zone it is negative. For notational efficiency and consistency with antecedent work (Farinotti et al. 2009a), we define an apparent balance rate $\widehat{b}=\dot{b}-\dot{H}$ which varies from a minimum value $\min (\widehat{b})$ to a maximum value $\max (\widehat{b})$. By sampling $\widehat{b}$ at regular intervals $\Delta \widehat{b}$ we generate a series of balance zones, where for zone $\alpha$ the limits are $\widehat{b}_{\alpha}-\frac{1}{2} \Delta \widehat{b} \leq \widehat{b}<\widehat{b}_{\alpha}+\frac{1}{2} \Delta \widehat{b}$. In this manner flowsheds in the region of interest can be partitioned into a series of banded zones. Letting $\Gamma_{\alpha}$ denote the curve that separates the lower boundary of zone $\alpha$ from the upper boundary of the zone immediately below it, $\Gamma_{\alpha}$ traces the lower boundary of a catchment area $A_{\alpha}$ for which $\widehat{b}>\widehat{b}_{\alpha}$. The ice discharge $\left(\mathrm{m}^{3} \mathrm{yr}^{-1}\right)$ across $\Gamma_{\alpha}$ is

$$
Q_{\alpha}=\int_{A_{\alpha}} \widehat{b} \mathrm{~d} A .
$$

Defining $l_{\alpha}$ as the length of $\Gamma_{\alpha}$, the length-averaged ice flux $\left(\mathrm{m}^{2} \mathrm{yr}^{-1}\right)$ traversing $\Gamma_{\alpha}$ is $\bar{q}_{\alpha}=Q_{\alpha} / l_{\alpha}$ 
Our aim is to use $\bar{q}_{\alpha}$ as the basis for estimating $\bar{\tau}_{\alpha}$, the characteristic bed stress along the $\Gamma_{\alpha}$ line. The volume flux of ice per unit width of channel is given by

$$
q=v_{\mathrm{s}} h+\frac{2 \mathcal{A}}{n+2} \tau^{* n} h^{2},
$$

(e.g., Cuffey and Paterson 2010, p. 310) where $q_{\mathrm{s}}=v_{\mathrm{s}} h$ is the sliding contribution and the second term represents ice flux due to creep

$$
q_{\mathrm{c}}=\frac{2 \mathcal{A}}{n+2} \tau^{* n} h^{2} .
$$

The parameters $\mathcal{A}$ and $n$ are the creep rate factor and exponent of Glen's flow law for ice. Taking $\tau^{*}=\rho g h \sin \theta,(13)$ can be rewritten as

$$
q_{\mathrm{c}}=\frac{2 \mathcal{A}}{n+2} \tau^{* n}\left(\frac{\tau^{*}}{\rho g \sin \theta}\right)^{2}
$$

leading to the expression

$$
\tau^{*}=\left[\frac{(n+2)(\rho g \sin \theta)^{2} q_{\mathrm{c}}}{2 \mathcal{A}}\right]^{\frac{1}{n+2}} .
$$

The key step in our approach is to take $\bar{q}_{\alpha}=q_{\alpha \mathrm{c}}+q_{\alpha \mathrm{s}}$, where $q_{\alpha \mathrm{c}}$ and $q_{\alpha \mathrm{s}}$ are the creep and sliding contributions to $\bar{q}_{\alpha}$ respectively, and then calculate the corresponding $\bar{\tau}_{\alpha}$. Rather than separately calculate $q_{\alpha s}$, we postulate that it is some fixed fraction of the total ice flux, and therefore take $q_{\alpha \mathrm{c}}=\xi q_{\alpha}$ and $q_{\alpha \mathrm{s}}=(1-\xi) q_{\alpha}$, to obtain

$$
\bar{\tau}_{\alpha}=\left[\frac{(n+2)(\rho g \overline{\sin \theta})_{\alpha} \xi q_{\alpha}}{2 \mathcal{A}}\right]^{\frac{1}{n+2}}
$$

where $\overline{\sin \theta}_{\alpha}$ is obtained from the ice surface slope averaged along the line $\Gamma_{\alpha}$. Next we assume that the calculated value for $\bar{\tau}_{\alpha}$ provides an estimate of $\tau_{\alpha}^{*}$ for the balance band $\alpha$ within a given flowshed. The resulting $\tau_{\alpha}^{*}$ value is then applied to the $(i, j)$ grid points that lie within balance band $\alpha$ to obtain $\tau_{i, j}^{*}$ for that balance band and flowshed. Finally these 
values are substituted into the cost minimization equation (9) which is solved to obtain the desired $H_{i, j}$ estimates.

Farinotti et al. (2009a) follow a similar line of thought. Assuming a simple elevation dependence for the net mass balance field, they evaluate the ice flux $q_{\mathrm{f}}$ and averaged surface slope $\bar{\theta}$ along the flow line and then apply the integrated form of Glen's flow law to express this in terms of ice thickness $h$ to obtain

$$
h=\left[\frac{(n+2) q_{\mathrm{f}}}{2 \mathcal{A}(C \rho g \sin \bar{\theta})^{n}}\right]^{\frac{n+2}{2}} .
$$

This is similar to our approach of estimating $\tau^{*}$ (Equation 16) and then using (3) to calculate the corresponding ice thickness. Their parameter $C$ is a dimensionless correction factor to account for the partitioning between creep and sliding contributions to ice flow. The main points of difference between our method and that of Farinotti et al. (2009a) are that we do not restrict our analysis to flowlines (and hence do not need to delineate them, automatically or otherwise) and that spatial smoothing is applied implicitly as an integral part of the inversion procedure (by means of the Laplacian interpolator), rather than as a distinct and explicit step (e.g., initial smoothing of the surface slope $\theta$ ).

\section{Technical matters}

This section contains much of the technical detail and justifications that underlie our approach to ice thickness estimation. The casual reader can skip this section and move directly to the section on performance analysis.

\section{a. Physical constants and glaciological parameters}

For the flow law parameters we take $n=3$ and $\mathcal{A}=2.4 \times 10^{-24} \mathrm{~Pa}^{-3} \mathrm{~s}^{-1}$, which match the values recommended in (Cuffey and Paterson 2010, Table 3.4), together with $\rho=910 \mathrm{~kg} \mathrm{~m}^{-3}$ 
for ice density and $g=9.81 \mathrm{~m} \mathrm{~s}^{-2}$ for the gravity acceleration. We make the approximation that sliding does not contribute to ice flow $\left(\xi=1\right.$ in (16)). In reality $\xi=\xi_{i, j}$ could vary from cell-to-cell in the model but lacking this information we apply a single value to all cells. Although for large active glaciers sliding can be significant, for most cells $\xi \approx 1$ is probably acceptable. In any case, we will show that $\xi$ is not a sensitive parameter of the inversion scheme.

\section{b. Calculation of surface slope}

There are several ways of calculating the magnitude of the surface slope by numerical differentiation of $S_{i, j}$. Our preferred method is to calculate the slope in each of four quadrants (NE, SE, SW, NW) and take the average. For example, for the NE quadrant,

$$
\left|\nabla S_{\mathrm{NE}}\right|_{i, j}=\left\{\left[\left(S_{i+1, j}-S_{i, j}\right) / \Delta x\right]^{2}+\left[\left(S_{i, j+1}-S_{i, j}\right) / \Delta y\right]^{2}\right\}^{\frac{1}{2}}
$$

and the quadrant-averaged slope is

$$
|\nabla S|_{i, j}=\frac{1}{4}\left[\left|\nabla S_{\mathrm{NE}}\right|_{i, j}+\left|\nabla S_{\mathrm{SE}}\right|_{i, j}+\left|\nabla S_{\mathrm{SW}}\right|_{i, j}+\left|\nabla S_{\mathrm{NW}}\right|_{i, j}\right] .
$$

A second consideration is how best to deal with the problem of small slopes. As already noted, expressions such as (2), (3), and (4) tend to infinity when $\theta \rightarrow 0$. We deal with this problem by applying a limiter to the slope expression (19) to avoid the $\left|\nabla S_{i, j}\right|=0$ limit. In the present work we use the slope limiter

$$
|\nabla S|_{\lim }= \begin{cases}\delta_{0}+\left(\delta_{1}-\delta_{0}\right)|\nabla S|^{2} / \delta_{1}^{2} & 0 \leq|\nabla S| \leq \delta_{1} \\ |\nabla S| & |\nabla S|>\delta_{1}\end{cases}
$$

with $\delta_{0}=0.01$ and $\delta_{1}=0.03$. This sets the minimum slope to $\delta_{0}=0.01$ which corresponds 
to an angle of $0.57^{\circ}$. When $|\nabla S|<\delta_{1}$ and the slope limiter is active we also reduce the tradeoff parameter $\chi_{i, j}$ in a systematic manner, tapering it to zero, as follows:

$$
\chi=\max \left[\frac{|\nabla S|-\delta_{0}}{\delta_{1}-\delta_{0}}, 0\right] \chi_{0} .
$$

Thus the minimum slope $\delta_{0}$ is never actually applied because the tradeoff parameter assigns no weight to the stress-based estimator when $|\nabla S| \leq \delta_{0}$.

\section{c. Balance zone delineation and calculation of width and slope at zone boundaries}

For gridded data the zone boundary $\Gamma_{\alpha}$ can be found algorithmically by searching for cells having $I_{i, j}=1$ (ice-covered) with $\hat{b}_{i, j}>\hat{b}_{\alpha}$ and one or more neighboring cells for which cells $\hat{b}_{i, j} \leq \hat{b}_{\alpha}$. For each flowshed and every balance zone, we calculate the length of the zone boundary $l_{\alpha}$, by summing over the length contribution from individual cells using a fluxweighted estimate of the length. Some form of weighting is necessary because the direction of ice flow is not usually aligned with the cell orientation; thus, for an individual cell having dimensions $\Delta x \times \Delta y$, its length contribution $\Delta l_{i, j}$ is unlikely to be $\Delta l_{i, j}=\Delta x$ or $\Delta y$. For the faces of the cell $(i, j)$, the surface slope components in the cardinal directions can be written

$$
\begin{array}{ll}
\nabla_{\mathrm{N}} S_{i, j}=\left(S_{i, j+1}-S_{i, j}\right) / \Delta y, & \nabla_{\mathrm{S}} S_{i, j}=\left(S_{i, j}-S_{i, j-1}\right) / \Delta y, \\
\nabla_{\mathrm{E}} S_{i, j}=\left(S_{i+1, j}-S_{i, j}\right) / \Delta x, & \nabla_{\mathrm{W}} S_{i, j}=\left(S_{i, j}-S_{i-1, j}\right) / \Delta x,
\end{array}
$$

and the corresponding outward creep flux magnitudes $\left[Q_{\mathrm{N}}\right]_{i, j},\left[Q_{\mathrm{E}}\right]_{i, j}$, etc. are proportional to the following:

$$
\begin{array}{ll}
{\left[w_{\mathrm{N}}\right]_{i, j}=\max \left(-\nabla_{\mathrm{N}} S_{i, j}, 0\right)^{n},} & {\left[w_{\mathrm{S}}\right]_{i, j}=\max \left(\nabla_{\mathrm{S}} S_{i, j}, 0\right)^{n}} \\
{\left[w_{\mathrm{E}}\right]_{i, j}=\max \left(-\nabla_{\mathrm{E}} S_{i, j}, 0\right)^{n},} & {\left[w_{\mathrm{W}}\right]_{i, j}=\max \left(\nabla_{\mathrm{W}} S_{i, j}, 0\right)^{n}}
\end{array}
$$


where the negative signs in the North and East terms have been applied so that outward cell fluxes are positive. As the length contribution for a single cell, we take the flux-weighted average for all cell walls through which there is an outward flux of ice, i.e.,

$$
\begin{aligned}
{\left[\Delta l_{\alpha}\right]_{i, j} } & =\frac{\left[w_{\mathrm{N}}\right]_{i, j} \Delta y+\left[w_{\mathrm{E}}\right]_{i, j} \Delta x+\left[w_{\mathrm{S}}\right]_{i, j} \Delta y+\left[w_{\mathrm{W}}\right]_{i, j} \Delta x}{\left(\left[w_{\mathrm{N}}\right]_{i, j}^{2}+\left[w_{\mathrm{E}}\right]_{i, j}^{2}+\left[w_{\mathrm{S}}\right]_{i, j}^{2}+\left[w_{\mathrm{W}}\right]_{i, j}^{2}\right)^{\frac{1}{2}}} \\
{\left[l_{\alpha}\right]_{g} } & =\sum_{G=g}\left[\Delta l_{\alpha}\right]_{i, j},
\end{aligned}
$$

where $\left[l_{\alpha}\right]_{g}$ is the length of the $\Gamma_{\alpha}$ balance zone boundary for the $g$-th flowshed.

\section{d. Ice masks and flowsheds}

It is important to distinguish between connected regions of ice that lie within a single ice mask and the individual ice flow units that can subdivide a mask. A high-elevation icefield, for example, might function as the common collection area for many individual glaciers but different flow units can be distinguished, sometimes very subtly, by topographic divides. The analogy with watersheds is obvious.

There is a substantial literature on algorithms for automated delineation of watersheds (e.g., Marks et al. 1984; Fairfield and Leymarie 1991; Meyer 1994; Tarboton 1997) but automated delineation of glacier flowsheds presents special challenges. Although the flows of water and ice are both gravity driven, glaciers have morphological differences that cause problems for conventional watershed algorithms. For example, a single glacier can have a multi-lobed terminus which, in a watershed algorithm, can be misinterpreted as multiple distinct glaciers, causing the algorithm to assign labels to many more flowsheds than actually exist. Rather than start from scratch we tailored the watershed algorithm included in the TopoToolbox (Schwanghart and Kuhn 2010) software package to deal with this problem (see next subsection for details). Figure 1 shows the results of applying this new flowshed delineation algorithm to a DEM of surface topography $\mathbf{S}$ (Fig. 1a) and ice mask I (Fig. 1b) 
to generate a flowshed map $\mathbf{G}$ (Fig. 1c) in a test example.

\section{e. Orphaned, fissioned, and problematic flowsheds}

Accurate delineation of glacier flowsheds is required for accurate estimation of $Q_{\alpha}$ (Equation 11) and $\bar{\tau}_{\alpha}$ (Equation 16). This subsection summarizes the corrective actions that are taken after applying a conventional watershed algorithm (Schwanghart and Kuhn 2010) to the DEM of an ice-covered surface. Three different kinds of problems are encountered: (i) Not all glacierized cells are assigned a watershed label and in effect they are "orphaned" by the watershed algorithm. (ii) The algorithm wrongly classifies glacier flow lines as flow divides and thus fissions a single glacier into one or more child glaciers. (iii) The lobate terminus of a single glacier can be wrongly dissected into fragments. Typically these fragments are small and lie mainly or entirely below the equilibrium line altitude (ELA) so they tend to be unviable in the sense that they have insufficient accumulation to maintain themselves.

Orphaned glacierized cells are readily identified because for these $I_{i, j}=1$ and $G_{i, j}$ is unassigned. If such cells are adjacent to cells that have been assigned a flowshed label they are merged with that flowshed; if they lack an adjacent neighboring flowshed they are assigned a new label and treated as an additional flowshed. This situation is very rare and arises from shortcomings of conventional watershed algorithms.

Fissioned flowsheds are a consequence of applying a watershed algorithm to glaciers that have a multilobed terminus. If the algorithm erroneously designates each lobe as a separate flowshed then this distinction will be preserved farther upstream even though the flowsheds are separated by a flowline rather than a flow divide. Fortunately the situation is easily detected. Cells $p$ and $q$ that are separated by a flowline boundary will tend to have the same slope direction whereas those that are separated by a flow divide boundary will tend to have opposite slope directions. A simple dot product test $\nabla_{x y} S_{p} \cdot \nabla_{x y} S_{q}$ is sufficient to discriminate between the two situations.

We classify a flowshed as "problematic" if $Q_{\alpha} \leq 0$ everywhere within it. For such 
flowsheds $\left[Q_{\text {ela }}\right]_{g}$ and $\left[l_{\text {ela }}\right]_{g}$ either vanish or are unacceptably small and the estimate of the ELA ice flux $\bar{q}_{\text {ela }}=Q_{\text {ela }} / l_{\text {ela }}$ fails. In many cases the unviable flowshed is contiguous to a viable one (for example when the unviable flowshed corresponds to some fragment of a glacier tongue which is adjacent to a viable flowshed). In this situation the unviable flowshed is merged with its viable neighbor (i.e., the label of the unviable flowshed is replaced by that of the viable flowshed and its area added to that of the viable flowshed). In situations when there is more than one viable contiguous flowshed the unviable flowshed is merged with its largest viable neighbor.

\section{f. Last resort estimates of bed stress}

In unusual situations it is impossible to calculate $\bar{\tau}_{\alpha}$ and a fall-back strategy is required. As an example, a flowshed that comprises a single ice cell cannot be decomposed into distinct accumulation and ablation areas and thus the mass balance analysis (11) that leads to estimates of $\bar{\tau}_{\alpha}$ cannot be carried out. For such cases we apply a stress-area scaling expression to estimate a single bed stress for the flowshed. The scaling relationship $V \propto A^{\gamma}$ which relates glacier volume to glacier area is derived in important papers by Bahr (1997) and Bahr et al. (1997). A lesser known but potentially useful result from the same work is $\tau^{*} \propto A^{\beta}$ which we write as

$$
\tau^{*}=k\left(A / A_{0}\right)^{\beta}
$$

where $k$ is a proportionality constant having units of stress, $A_{0}$ is a characteristic glacier area (we arbitrarily take $\left.A_{0}=1 \mathrm{~km}^{2}\right)$, and $\beta=2(\gamma-1)-\frac{1}{2}$. The scaling theory yields $\gamma=11 / 8=1.375$ whereas a prior linear regression of data from 63 mountain glaciers (Chen and Ohmura 1990) yielded $\gamma=1.36$. Accepting $\gamma=11 / 8$ gives $\beta=1 / 4$, indicating a weak dependence of bed stress on glacier area. The proportionality constant $k$ is estimated by evaluating the statistic

$$
k_{g}=\frac{\left[\tau_{\text {ela }}\right]_{g}}{\left(A_{g} / A_{0}\right)^{\frac{1}{4}}}
$$


for all viable flowsheds and then calculating the mean using a weighted average. In (27) $k_{g}$ is the calculated proportionality constant, $\left[\tau_{\text {ela }}\right]_{g}$ is the estimated bed stress at the ELA, and $A_{g}$ is the area of the $g$-th flowshed. We find that root area-weighting

$$
\langle k\rangle=\frac{\sum_{g} \sqrt{A_{g}} k_{g}}{\sum_{g} \sqrt{A_{g}}}
$$

gives satisfactory results.

\section{g. Adjustment of the mass balance field}

For a glacier flowshed that is delineated by the curve $\mathcal{C}$ which encloses a surface area $A$, the integral form of the expression for ice volume balance is given by

$$
\frac{\mathrm{d}}{\mathrm{d} t} \int_{A} H \mathrm{~d} A=\int_{A} \dot{b} \mathrm{~d} A
$$

which expands to

$$
\int_{A} \dot{H} \mathrm{~d} A+\int_{\mathcal{C}} \mathbf{n} \cdot \mathbf{q} \mathrm{d} \mathcal{C}=\int_{A} \dot{b} \mathrm{~d} A
$$

where $\mathbf{q}=\mathbf{v} H, \mathbf{v}$ is the column-averaged ice velocity vector, and $\mathbf{n}$ is the outward normal vector (in two dimensions) to the curve $\mathcal{C}$. The second lefthand-side term of (30) is associated with an increase or decrease in the flowshed area and merits special discussion. For advancing glaciers, such as those undergoing a surge, the term can be non-negligible and positive. For retreating glaciers, upflow velocities are non-physical and $\mathbf{v}$ vanishes along $\mathcal{C}$. For most situations, especially in a warming climate where glacier retreat prevails, the term can be neglected and (30) gives

$$
\int_{A}(\dot{b}-\dot{H}) \mathrm{d} A=\int_{A} \widehat{b} \mathrm{~d} A=0 .
$$

In reality the flowshed boundary $\mathcal{C}$ and enclosed area $A$ as well as the surface balance 
rate $\dot{b}$ and thinning rate $\dot{H}$ are imperfectly known so that when the integration of (31) is performed using imperfect quantities $A^{( \pm)}, \dot{b}^{( \pm)}$, and $\dot{H}^{( \pm)}$the result is unlikely to vanish. For this case

$$
\int_{A^{( \pm)}}\left(\dot{b}^{( \pm)}-\dot{H}^{( \pm)}\right) \mathrm{d} A^{( \pm)}=\int_{A^{( \pm)}} \widehat{b}^{( \pm)} \mathrm{d} A^{( \pm)}=b_{0} A^{( \pm)},
$$

where $b_{0}$ is a constant and $A^{( \pm)}$is the estimated flowshed area. A non-vanishing result in (32) can lead to systematic over- or underestimates of the ice discharge $Q_{\alpha}$ in (11) and thus to errors in estimates of basal stress and ice thickness. If, for example, $b_{0}$ is negative then $Q_{\alpha}$ will vanish along a line $\Gamma_{\alpha}$ which is upglacier from the glacier terminus. Thus in the region between the terminus and $\Gamma_{\alpha}$ the computed ice discharge will be negative, corresponding to up-slope transport of ice. To deal with this situation we adjust the estimated apparent mass balance field $\widehat{b}^{( \pm)}$by simply subtracting the balance error $b_{0}$, in effect assuming $\widehat{b}^{( \pm)}=$ $\dot{b}^{( \pm)}-\dot{H}^{( \pm)}-b_{0}$ so that the computed integral (31) vanishes as it should. We refer to this procedure as "balance adjustment".

h. Influence of uncertainty in values of flow law coefficient and flow partitioning parameter

The expected sensitivity of ice thickness inversions to uncertainty in model parameters such as the flow law coefficient $\mathcal{A}$ and flow partitioning $\xi$ can be inferred from the relationship

$$
H=\frac{1}{\rho g \sin \theta \cos \theta}\left[\frac{(n+2)(\rho g \sin \theta)^{2} \xi q}{2 \mathcal{A}}\right]^{\frac{1}{n+2}}
$$

obtained from (3) and (15). Concentrating attention on the parameters $\mathcal{A}$ and $\xi$ we assume that $H=H(\mathcal{A}, \xi)$ and take logarithmic derivatives to obtain

$$
\frac{\mathrm{d} H}{H}=\frac{1}{n+2}\left(\frac{\mathrm{d} \xi}{\xi}-\frac{\mathrm{d} \mathcal{A}}{\mathcal{A}}\right)
$$

With $n=3$ the fractional change in ice thickness is $1 / 5$ th the fractional change in $\xi$ and $\mathcal{A}$, with increased $\xi$ leading to increased ice thickness and increased $\mathcal{A}$ leading to decreased 
thickness. Clearly the thickness estimates are not sensitively dependent on uncertainty in these parameters, a result that we also have confirmed by testing the effect of varying $\mathcal{A}$ and $\xi$ in the inversion models.

\section{i. Shape factors and debris cover}

Paul and Linsbauer (2011) apply a shape factor correction to their bed stress estimates but assume this to be constant at $f=0.80$ so its only effect is to systematically increase the estimated ice thickness. In contrast, Farinotti et al. (2009a) do not include a shape factor although their correction factor $C$ in (17) could be adjusted to include a channel shape correction. We do not include an explicit shape factor because we are wary of applying an all-embracing correction factor to our thickness estimates, preferring to view the role of shape factors as a potential source of systematic error that is subject to scrutiny.

In their analysis of Swiss Glaciers, Farinotti et al. (2009a) include the affect of debris cover on mass balance. At present Tiedemann Glacier, BC is one of the few glaciers in our study region for which a debris mask has been generated. For our study region this effort would need to be expanded before we could follow their example.

\section{j. Regularization}

We use $\nabla_{x y}^{2} H_{i, j}$ (e.g., Equation 6) to smooth the estimated ice thickness. An alternative approach, which seems reasonable but leads to problems, is to smooth the bed topography $B_{i, j}=S_{i, j}-H_{i, j}$ rather than the ice thickness $H_{i, j}$. This can lead to negative ice thickness estimates which must then be dealt with. To avoid this difficulty we use the $\nabla_{x y}^{2} H$ regularization and have also tested the $\left|\nabla_{x y} H_{i, j}\right|$ regularization, finding that it gives comparable results. 


\section{Performance analysis and error estimates}

To assess the performance of the ice thickness estimation scheme, we used a numerical ice dynamics model to generate synthetic ice cover over known deglacierized topography and then tested the skill of the inversion scheme for a range of situations. A potentially serious shortcoming of this stratagem is that the ice dynamics model could have unknown physical or numerical defects that cause it to produce non-physical representations of glaciers.

The ice dynamics model was originally developed by C. G. Schoof and is based on the shallow ice approximation; it uses a semi-implicit finite-difference method together with flux limiters to solve mass conservation and vertically-integrated momentum equations on a rectangular grid (Jarosch et al. 2012b). The basic equations of the model are

$$
\begin{aligned}
\dot{H} & =\dot{b}-\operatorname{div}_{x y} \mathbf{q} \\
\mathbf{q} & =-\frac{2 \mathcal{A}(\rho g)^{n}|\nabla S|^{n-1}}{n+2} H^{n+2} \nabla S+\mathbf{v}_{\mathrm{s}} H_{\mathrm{s}},
\end{aligned}
$$

with the parameter assignments $\mathcal{A}=2.4 \times 10^{-24} \mathrm{~Pa}^{-3} \mathrm{~s}^{-1}, n=3, \rho=910 \mathrm{~kg} \mathrm{~m}^{-3}, g=$ $9.81 \mathrm{~m} \mathrm{~s}^{-2}$, and $\mathbf{v}_{\mathrm{s}}=0$. We assume the glaciers are isothermal at the melting temperature of ice so there is no need to include an energy equation. For the vast majority of glaciers in the study area this is likely to be a valid assumption but it would become dubious if applied universally to glaciers of the Yukon interior, farther to the north. Huss and Farinotti (2012) face this problem in estimating the glacier contribution to global ice volume and use the mean annual temperature at the ELA as a basis for modifying the creep rate factor $\mathcal{A}$ in expressions such as our Equation 16. It follows from (17) that the effect of reducing the rate factor is to increase the estimated ice thickness.

We used DEMs for unglacierized mountainous topography in British Columbia (BC) and the Yukon Territory (YT) to represent the deglaciated surface $B(x, y)$. The labels and coordinates of the map centers for these regions are $\mathrm{BC} 1\left(55.4635^{\circ} \mathrm{N}, 124.8151^{\circ} \mathrm{W}\right), \mathrm{BC} 2$ $\left(58.9000^{\circ} \mathrm{N}, 125.8714^{\circ} \mathrm{W}\right), \mathrm{BC} 3\left(59.4545^{\circ} \mathrm{N}, 130.3566^{\circ} \mathrm{W}\right)$, and $\mathrm{YT} 1\left(61.6014^{\circ} \mathrm{N}, 133.3684^{\circ} \mathrm{W}\right)$. 
Ice cover was then grown on this landscape by applying simplified mass balance forcings of the form

$$
\begin{aligned}
\dot{b}(x, y, t) & =\frac{\mathrm{d} \dot{b}^{-}}{\mathrm{d} z} \min \left(S-z_{\text {ela }}(t), 0\right)+\frac{\mathrm{d} \dot{b}^{+}}{\mathrm{d} z} \max \left(S-z_{\text {ela }}(t), 0\right) \\
z_{\text {ela }}(t) & =z_{\mathrm{L}}+\frac{1}{2}\left(z_{\mathrm{H}}-z_{\mathrm{L}}\right)\left(1+\cos \left(2 \pi t / T_{0}\right)\right)
\end{aligned}
$$

where $\mathrm{d} \dot{b}^{-} / \mathrm{d} z$ and $\mathrm{d} \dot{b}^{+} / \mathrm{d} z$ are constant elevation gradients of mass balance, $z_{\mathrm{L}}$ and $z_{\mathrm{H}}$ are the lowest and highest elevation of the ELA, and $T_{0}$ is the assumed periodicity of the climate cycle. We explore a wide range of mass balance forcings for steady-state runs involving the four test regions by varying $z_{\text {ela }}$ (Fig. 2). The resulting ice masks, though not the ice thicknesses, are quite similar for the low- and high-rate models so we only plotted those for the high-rate case.

The numerical ice dynamics model generates time-evolving surface topography $S(x, y, t)$ from which we can compute the ice thickness $H(x, y, t)$, surface slope $\nabla S(x, y, t)$, timeevolving ice mask $I(x, y, t)$, and flowshed map $G(x, y, t)$. We then perform calculations to estimate $\left[Q_{\alpha}\right]_{g},\left[l_{\alpha}\right]_{g},\left[\bar{q}_{\alpha}\right]_{g},\left[\bar{\tau}_{\alpha}\right]_{g}$, and, finally, $H_{i, j}$ at any given snapshot time $t$. Because $B_{i, j}$ is known a priori, the true ice thickness $H_{i, j}$ is known and can be compared with the estimated thickness $\widetilde{H}_{i, j}$ to yield the estimation error $\varepsilon_{i, j}=\widetilde{H}_{i, j}-H_{i, j}$. We use this approach to evaluate the performance of the thickness estimator and assess the influence of assumptions and parameter assignments on performance (Table 1). For this suite of runs the ELA was set to a constant value $\left(z_{\text {ela }}=z_{\mathrm{L}}=z_{\mathrm{H}}\right)$ and the simulations continued until a steady-state was achieved. Model names, such as BC1.1550H, combine information about the geographical site (BC1), ELA $(1550 \mathrm{~m})$, and whether the model is strongly-forced (large elevation gradients of mass balance rate $\mathrm{d} \dot{b}^{-} / \mathrm{d} z$ and $\mathrm{d} \dot{b}^{+} / \mathrm{d} z$ labeled $\mathrm{H}$ (high)) or weaklyforced L (low gradients). For each site and ELA there exists an H and L pair of models. Interestingly, for each model pair the area fractions $\alpha_{\mathrm{I}}$ do not differ much between the $\mathrm{H}$ model and the $\mathrm{L}$ model but the ice volumes differ by roughly a factor of two. This has 
possible implications for the effectiveness of the volume-area scaling approach (e.g., Bahr 1997; Bahr et al. 1997) which would predict that glaciers having similar area would also have similar volume assuming that the scaling constant is universal. To be fair, Bahr has never viewed the scaling constant as universal but users of his theory have occasionally treated it as such.

\section{a. Results of performance test}

There are substantial performance differences among the model runs analyzed and among the performance measures for any given run (Table 2). Rather than dwell on individual cases we shall treat the 32 model runs as an ensemble and summarize the ensemble properties by taking the mean and median of the performance indicators for each member of the ensemble. These indicators include $r$ (the correlation coefficient between the true ice thickness $H_{i, j}$ and the estimated thickness $\widehat{H}_{i, j}$, the mean thickness error $\left\langle\widetilde{H}_{i, j}-H_{i, j}\right\rangle$, standard error $\sigma=\left\langle\left[\widetilde{H}_{i, j}-\left\langle H_{i, j}\right\rangle\right]^{2}\right\rangle$, and fractional error in ice volume $(\widetilde{V}-V) / V$. The average and median properties of the thickness estimates are good but among members of the ensemble there are some conspicuous exceptions.

We single out model YT1·1700H for additional attention. Relative to other members of the ensemble, the performance indicators are neither bad nor good: of the 32 model runs analyzed, it ranks 24th for standard deviation $(23.29 \mathrm{~m})$ and rms ice thickness error $(23.29 \mathrm{~m}), 12$ th for mean thickness error $(2.27 \mathrm{~m})$, and 9 th for fractional volume error $(4.40 \%)$. Nonetheless the overall quality of the ice thickness estimate is encouraging. Plots of the estimated ice thickness vs. the ice thickness in the simulation runs (Fig. 3a) show good correspondence except for large values of ice thickness, where the estimated thickness greatly exceeds the true thickness. However, the number of these outliers is small relative to the total number of points. A histogram of the distribution of the ice thickness estimation error (Fig. 3b) shows that the distribution is slightly asymmetrical, consistent with the fact that thickness cannot be negative. The distribution functions for the actual and estimated ice 
thickness (Fig. 3c) match reasonably well.

A suite of maps illustrates the performance of the estimation model for this particular case (Fig. 4). The assigned bed stress, based on (16) with $\xi=1$ and mass balance adjustment of each flowshed to enforce (31), is shown in Fig. 4a. Also shown are the estimated ice thickness (Fig. 4b), the thickness error (Fig. 4c), and the resulting estimate of bed surface topography (Fig. 4d). It is reassuring that the estimated bed surface topography actually resembles a deglaciated landscape because our larger aim is to use such estimates as the starting geometry for projection modeling of the climate-forced deglaciation of western Canada.

Similar performance tests have been carried out for models having a cyclic variation in ELA. We accomplish this by setting $z_{L}=z_{0}-\Delta z_{\text {ela }}, z_{H}=z_{0}+\Delta z_{\text {ela }}$, and $t_{0}=1000 \mathrm{yr}$ in (38) and running the model for 80000 simulation years until a periodically repeating state is achieved. Then for each model we select output states from the final cycle of the simulation that correspond to intervals of fastest deglaciation and fastest reglaciation. Owing to system lags and geometrical effects these usually differ from the times at which the ELA is changing most rapidly so the snapshot times can vary among models. Transient model outputs are assigned labels such as $\mathrm{BC} 1 \cdot 1550 \pm 100 \mathrm{H} \uparrow$ or $\mathrm{BC} 1 \cdot 1550 \pm 100 \mathrm{~L} \downarrow$ where $\mathrm{BC} 1$ denotes the region, 1550 , the mean ELA in metres, \pm 100 the amplitude of the sinusoidal elevation excursions, $\mathrm{H}$ or L, a high or low mass balance forcing rate, and $\uparrow$ a maximally increasing or $\downarrow$ maximally decreasing rate of ice area change.

We summarize the results of performance tests carried out when the glacier cover is rapidly decreasing (Table 3) or rapidly increasing (Table 4). Comparing these results with those in Table 2 indicates that the ensemble mean and median of mean thickness error and fractional volume error are larger for the transient inversions than for the steady-state ones. Interestingly, for both the deglaciation and reglaciation datasets there is a strong positive bias to the mean thickness error and fractional volume error, so for both situations there is a tendency to overestimate the ice volume. We have no explanation for this. Of the 64 cases listed in Tables 3 and 4, only BC3·1650 $1100 \mathrm{H} \downarrow$ yields an underestimate of average ice 
thickness and volume. Ensemble mean and median thickness error and fractional volume error are greater, by a substantial margin, for the situation of rapid reglaciation than for rapid deglaciation. Worldwide, rapid deglaciation predominates (Lemke et al. 2007) so for this situation the smaller errors should apply.

\section{Application to glaciers of western Canada}

\section{a. Comparison with thickness measurements on three glaciers}

We have previously commented that actual measurements of ice thickness in the study region are few and their usefulness for testing the ice thickness estimation method is open to question. The main sources of difficulty are that the geographical locations and true elevations of the measurements are not well controlled and that substantial surface lowering has occurred between the time that the measurements were taken and the date of the digital elevation model and ice mask used in the inversion. We have attempted to recover the measurement positions as best we can and, where possible, have applied the 1985-1999 measurements of surface elevation change (Schiefer et al. 2007) to correct for thickness changes that have occurred between the measurement dates and the estimation date.

Figure 5 compares measured and estimated ice thicknesses for the three glaciers in the study area that have been geophysically surveyed and for which a published record exists. For Athabasca Glacier $\left(52.19^{\circ} \mathrm{N}, 117.26^{\circ} \mathrm{W}\right)$ seismic sounding and drilling data were collected from 1959-1961 and are tabulated in Paterson's doctoral thesis (Paterson 1962). Although measurement locations were precisely determined using optical surveying, the survey coordinate system was not georeferenced and lacks an elevation datum. It was therefore necessary to adjust its orientation and offset to align with the DEM of estimated bed topography. Since 1961 the surface elevation and spatial extent of the glacier have changed substantially. The Southern Rockies region, which contains both Athabasca and Peyto Glaciers, includes parts of British Columbia and Alberta. For BC glaciers, the Schiefer et al. (2007) time-averaged 
thinning rates were calculated by subtracting two DEMs to obtain cell-by-cell estimates. Both Athabasca and Peyto Glaciers are located in Alberta and one of the two DEMs is not defined beyond the BC boundary. Thus we have applied less accurate and more coarselyresolved elevation-dependent estimates (Schiefer et al. 2007, Fig. 3) to obtain a thinning correction. The average amount of thinning between 1960 and 2005 was $52.4 \mathrm{~m}$.

Radio echo soundings of Peyto Glacier $\left(51.66^{\circ} \mathrm{N}, 116.56^{\circ} \mathrm{W}\right)$, documented in Holdsworth et al. (2006), were taken from 1983-1985. The results are tabulated in Table 1 of that work and include UTM coordinates of all measurement sites. Accepting these at face value (making plausible assumptions concerning the assumed geodetic datum), the data need only be corrected for changes in ice extent and surface thinning. Using the same elevationdependent relationship as for Athabasca Glacier, we found the average glacier-wide thinning for $1984-2005$ to be $14.3 \mathrm{~m}$.

For Salmon Glacier $\left(56.15^{\circ} \mathrm{N}, 130.19 \mathrm{~W}\right)$, in British Columbia, depths were measured using seismic sounding and drilling (Mathews 1959; Doell 1963) but were presented as plotted cross sections and maps. We extracted thickness data from a contour map of surface and bed elevation (Doell 1963, Fig. 5) so the associated uncertainties are considerable. The average thinning for $1956-2005$ was $107.7 \mathrm{~m}$ and ranged from $145.9 \mathrm{~m}$ to $32.4 \mathrm{~m}$. Gravity survey results are also available for Athabasca Glacier (Kanasewich 1963) and Salmon Glacier (Russell et al. 1960) but these are expected to be less accurate than direct sounding methods and have not been used.

Figure 5a shows the estimated ice thickness vs. measured ice thickness for the three glaciers with no correction for ice thinning. Figure 5b shows the same data but corrected for surface lowering. Although the thinning correction improves the agreement between measurements and estimates there is still a general tendency for our model to underestimate the thickness of the three glaciers. Some of the disagreement can be attributed to uncertainties in the measurement locations and the thinning correction but one plausible explanation for underestimated ice thickness is that the stress system is more complex than that for an 
inclined slab (Equation 2). The simplest approach to correcting for this situation is to introduce a dimensionless shape factor $0<f \leq 1$ (e.g., Nye 1964; Cuffey and Paterson 2010) and rewrite the bed stress as $\tau^{*}=f \rho g h \sin \theta$ which, reworking (13), leads to a systematic increase in estimated ice thickness by a factor $F=(1 / f)^{n / n+2}$. Taking $n=3$ and assuming $f=0.70$, a reasonable value, gives $F=1.24$. Multiplying the estimated ice thickness values by this "correction factor" yields an improved fit to the 1:1 line in Figure 5b but we have substantial misgivings about the trustworthiness of this three-glacier performance test and many concerns about applying this as a global correction to a region that contains more than 17000 glaciers. Thus for our thickness estimates we take $f=1$ and flag this assumption as a potential source of error. The shape factor is only relevant to the portions of glaciers that flow through confined channels so, for icefields, $f=1$ is more likely to apply. Furthermore the shape-corrected bed stress is only meant to apply along the central flow axis of confined channels and not near the channel walls.

\section{b. Ice volume estimates}

Finally we apply the ice thickness estimation method that has been described and validated in previous sections to the problem of estimating the ice volume and subglacial topography of all glaciers in the study region. Our ice mask (Fig. 6) represents glacier extent in Alberta and British Columbia from 2005 AD with subregions chosen to match those of Bolch et al. (2010). The DEM for BC and AB is from the Shuttle Radar Topography Mission (SRTM) version 4.1 with $90 \mathrm{~m}$ spatial resolution (Farr et al. 2007) and downloaded from http://srtm.csi.cgiar.org/.

For the $\mathrm{BC}-\mathrm{AB}$ study region we relied mainly on ice masks that were derived from Landsat ETM data and based on scenes captured in 2005 (Bolch et al. 2010). The original masks are in the form of vector graphic polygons but, for present purposes, have been converted to rasterized objects that align with the $200 \mathrm{~m} \times 200 \mathrm{~m}$ cells of our computational grid. The St. Elias (SE) and Northern Coast (NC) subregions required special treatment because the 
Bolch et al. (2010) masks are truncated at the British Columbia-Alaska boundary. For ice thickness estimation we require intact ice masses in order to integrate the ice discharge as in Equation 11 so for these subregions we used the same ice masks as Berthier et al. (2010). These masks were extracted from the GLIMS glacier database (Beedle 2006) and are mainly derived from USGS sources but are heterogeneous in terms of the data sources and dates of acquisition. The most serious consequence of this methodological inconsistency is that our calculated ice areas (hence estimated volumes) for the SE and NC subregions differ slightly from those tabulated in Bolch et al. (2010).

We model the mass balance fields (Anslow et al. in preparation) using climate fields that have been downscaled from the North American Regional Reanalysis (Mesinger et al. 2006) following a methodology that has been described and validated by Jarosch et al. (2012a). As input DEMs for our downscaling methods, we resample the 90-m SRTM dataset at $1 \mathrm{~km}$ for precipitation and $200 \mathrm{~m}$ for surface topography and temperature. We do not consider knowledge of the glacier mass balance fields to be an onerous requirement because our main motivation for estimating subglacial topography is to perform computer simulations of the climate-forced deglaciation of our study regions. Mass balance fields are essential for any serious modeling effort, so we would require these in any case.

Because few contemporary glaciers are in balance with their climate forcings, we also require estimates of the ice thinning (or thickening) rates. We are obliged to use two different sources for these data. Within British Columbia (BC) the spatial variation of thinning rates is based on the datasets published by Schiefer et al. (2007) and applies to the time interval 1985-1999. These were generated by differencing the SRTM DEM for February 2000 and a ca. 1985 DEM based on aerial photography (Anonymous 1992). We reprojected these data from the native BC Albers projection to the Lambert conical conformal projection used in the NARR and then resampled at $200 \mathrm{~m}$ to match our computational grid. For Alberta and those parts of Alaska and Yukon that are contiguous to BC, no suitable DEMs existed for the 1980s so spatial representation of the thinning rate was not possible. For these cells, 
beyond the limits of the $\mathrm{BC}$ data, we applied elevation-dependent thinning rates using data from Fig. 3 of Schiefer et al. (2007).

Downscaled NARR climate fields are used to construct annually-averaged glacier mass balance rates for the study region. The degree of time-averaging that should be applied to these data is not clearcut and is likely to depend on glacier size as well as other factors. A one-year time-average is too short because it is considerably smaller than representative values of the glacier response time. However, in a warming climate, a century-long time average might assign too much weight to the past state of glaciers. This sensitivity of ice volume estimates depends on how the mass balance field is time-averaged (Table 5). We take decadal averages over the time spans 1980-1989, 1990-1999, and 1999-2008 as well as the 29-year average 1980-2008 and denote these time-averaged balance rates by $\bar{b}_{1980}^{1989}$, etc. By repeating the ice thickness inversions for each of the time-averaged forcings, we calculate the sea-level-equivalent (SLE) volume contribution from each of the sub-regions. For this dataset, at least, the differences that result from different time-averaging treatments are small and we conclude that the duration of time-averaging has a minor influence on the estimates. Our preferred result is that for $\bar{b}_{1980}^{2008}$ (the rightmost column in Table 5).

We foresee that good estimates of the time-averaged thinning rate fields will not necessarily be available for all regions where ice thickness estimates are needed. Various treatments of the thinning rate affect the inversion results (Table 6). The different possibilities that were considered are indicated by $\dot{H}=0$ (thinning rate assumed to vanish), $\dot{H}=\dot{H}(z)$ (elevation-dependent rate), and $\dot{H}=\dot{H}(x, y)$ (space-varying rate). The preferred results are those for space-varying rate (two rightmost columns) and match to the preferred result in Table 5. The space-varying thinning rate yields the lowest estimate of SLE volume and the differences between the $\dot{H}=0$ column the $\dot{H}=H(x, y)$ column are too large to justify ignoring the thinning rate if this information is available. If a space dependent rate is not known then adopting an empirically-based elevation-dependent rate is preferable to simply ignoring the effect. 
We also calculate the total number of ice masses (i.e., unique ice masks with no regard to whether they constitute one or more flowsheds) and the total number of delineated flowsheds (Table 6). For gridded data each cell has neighbors to the North, East, South, and West as well as diagonally-situated neighbours to the NE, SE, SW, and NW. Whether one allows diagonal connectivity (C8) or disallows it (C4) influences the results of these calculations. We assume C8 connectivity for ice masses and flowsheds (Table 6). The total ice area for each region is given in column 4 and for most regions closely matches that presented in Bolch et al. (2010); this is not surprising because we used the same ice masks. However our ice areas for the SE and NC regions differ from those of Bolch et al. (2010) because for these regions we use the USGS ice masks that spanned the political boundary between BC and Alaska.

We now compare the estimated sea level equivalent from our inversion method to those derived from volume-area scaling (Bahr 1997; Bahr et al. 1997; Radić and Hock 2010). From $V=K\left(A / A_{0}\right)^{\gamma}$ with $\gamma=1.375$ and $K=0.036544 \mathrm{~km}^{3}$ (which with dimensional adjustments corresponds to the $c=0.2055 \mathrm{~m}^{3-2 \gamma}$ adopted by Chen and Ohmura (1990) and Radić and Hock (2010)) the estimated volume using the scaling formula is $6.214 \mathrm{~mm}$ SLE (ice volume $2470 \mathrm{~km}^{3}$ ). It is interesting that the volume-area scaling method yields ice volumes that are not vastly different from those obtained by our estimation technique. Before error analysis, our best estimate of the present day (ca. 2005) ice volume for glaciers of British Columbia and Alberta is $5.83 \mathrm{~mm}$ SLE (ice volume $2320 \mathrm{~km}^{3}$ ).

\section{c. Error analysis}

Table 7 represents an attempt to summarize and quantify the known sources of error. For temperate ice, the flow law coefficient is uncertain and recent studies cited in Cuffey and Paterson (2010) (Hubbard et al. 1998; Gudmundsson 1999; Adalgeirsdóttir et al. 2000; Albrecht et al. 2000; Truffer et al. 2001), in which glacier flow modeling is used to calibrate the flow law, have led to a substantial revision of $\mathcal{A}$. Among these studies there is excellent 
agreement and $\mathcal{A}=2.4 \pm 0.5 \times 10^{-24} \mathrm{~Pa}^{-3} \mathrm{~s}^{-1}$ encloses their spread. We assume that all ice in the study region is temperate so there is no need to consider temperature effects on $\mathcal{A}$.

From (34) it is apparent that errors in the flow law coefficient do not strongly affect the thickness estimates. A non-sliding glacier will be thicker than a sliding glacier in the same setting subjected to the same mass balance forcing. Thus our assumption that $\xi=1$ (no sliding) contributes to an overestimation of ice thickness. In reality $\xi$ varies from glacier-toglacier and from point-to-point in any given glacier. Although for parts of some fast-flowing surging glaciers $\xi<0.1$, we suspect that $\xi \approx 0.8$ is typical of the majority of healthy mountain glaciers; for glaciers in retreat, the sliding contribution is likely to be even smaller. Lastly, (34) indicates that ice thickness estimates are comparatively insensitive to uncertainly in $\xi$.

We set the default value of the tradeoff parameter to $\chi_{0}=0.4$ in order to smooth out the estimated bed topography but this also leads to a reduction in estimated thickness. With $\chi \rightarrow 1$ the average estimated thickness is maximized but the exaggeration of bed topography is unacceptable and could pose problems when used as the substrate geometry for ice dynamics modeling. By rerunning the inversion model for a range of $\chi_{0}$ values we conclude that for $\chi_{0}=0.4$ an overestimate of ice volume is unlikely and that underestimation should not exceed $5 \%$ (0.3 $\mathrm{mm}$ SLE).

Other potential sources of systematic error are associated with suspected errors in the ice masks for the St. Elias and Northern Coast subregions and with the physical assumptions of the inversion model. As previously discussed, the ice mask areas for the SE and $\mathrm{NC}$ subregions differ slightly from than those calculated by Bolch et al. (2010) and for which his estimated error is small. If one accepts the Bolch et al. values as correct then the ice volume for these subregions, taken together, could be underestimated by as much as $0.1 \mathrm{~mm}$ SLE.

The modeling assumptions that warrant scrutiny are (i) that $\tau^{*}=\rho g h \sin \theta$ provides an acceptable approximation to the bottom stress irrespective of proximity to valley walls, and (ii) that $\bar{\tau}_{\alpha}$ calculated using (16) yields a useful estimate of $\tau^{*}$. We view this as the weakest link of the inversion procedure and one that could lead to underestimates of ice thickness 
and thus of total ice volume. The magnitude of this underestimate might be as large as $1.5 \mathrm{~mm}$ SLE.

For sources of systematic error that would lead to an overestimate of ice volume (Table 7) errors total to $0.6 \mathrm{~mm} \mathrm{SLE}$; for sources that would lead to an underestimate the total is $2.2 \mathrm{~mm}$ SLE. However, it is highly unlikely that the combined systematic errors would conspire to produce either of these extrema but deciding how best to combine systematic and random error contributions is a subjective task. For each source of systematic error we shall postulate a form for the error distribution function and use the lower and upper range estimates to guide our assignment of the mean value and standard deviation for each distribution. Thus, for the flow law coefficient $\mathcal{A}$ the error is assumed to be Gaussian distributed with zero mean and standard deviation of $\sigma=0.3 \mathrm{~mm}$. The remaining sources of systematic error are either all-negative (e.g., $\xi$ errors) or all-positive (e.g., model physics and shape factor $f$ ) and we approximate these by exponential distributions. A convenient property of exponential distributions is that the magnitudes of the mean and standard deviation are identical. The range limits in Table 7 are intended to indicate extreme limits of the individual distribution functions so we shall associate the magnitudes of the range limits with the $3 \sigma$ values of the exponential distribution. The sign of the limit determines whether the exponential function is left- or right-sided. The remaining errors are random and assumed to be Gaussian distributed with zero mean and standard deviations given by the range values. Thus, for example, the standard deviation of the DEM elevation error is $\sigma=0.001 \mathrm{~mm}$ SLE. A Monte-Carlo procedure (with $N=100000$ ) was then followed to generate a statistical dataset formed by summing the random contributions from each error term and the mean and standard deviation were then calculated for the combined dataset. The mean value of the combined error is $0.54 \mathrm{~mm}$ and its standard deviation is $0.55 \mathrm{~mm}$. Thus we conclude that when random and systematic errors are taken into account the estimated ice volume is $6.3 \pm 0.6 \mathrm{~mm} \mathrm{SLE}$ or $2530 \pm 220 \mathrm{~km}^{3}$. (It is a simple matter to convert between glacier ice volume and the equivalent sea-level rise in Table 7 . Taking the 
ocean area as $3.62 \times 10^{8} \mathrm{~km}^{3}$ (Lemke et al. 2007) with $\rho=910 \mathrm{~kg} \mathrm{~m}^{-3}$ and $\rho_{\mathrm{w}}=1000 \mathrm{~kg} \mathrm{~m}^{-3}$ the conversion relations are $1 \mathrm{~km}^{3}$ ice $=2.51 \mu \mathrm{m} \mathrm{SLE}$ and $1 \mathrm{~mm} \mathrm{SLE}=398 \mathrm{~km}^{3}$ ice.)

\section{Discussion and conclusions}

Scientific interest in the thickness of glaciers (e.g., Agassiz 1847) preceded, by almost a century, the advent of geophysical instruments capable of measuring this quantity. Recent interest has focussed on ice volume and the potential contribution to sea level rise. Volume-area scaling (Chen and Ohmura 1990; Bahr 1997; Bahr et al. 1997; Radić and Hock 2010) was a first response to the problem of estimating the volume of Earth's mountain glaciers and has the attraction of involving a readily observable quantity (area) as its sole input. Our estimates of ice volume (Table 6) show good agreement with those based on volume-area scaling. We suspect that, in part, this is fortuitous but both methods start from similar physical assumptions so the result is not altogether surprising. Whatever the merits of estimating ice volume using volume-area scaling, the method has limited usefulness for estimating the map of bed topography lying beneath the surface of glaciers - essential information for using computational ice dynamics models to project the future volume and extent of Earth's mountain glaciers. However, the use of geophysical inversion methods to estimate bed topography has its own pitfalls. As emphasized by Bahr et al. (1994) the problem of calculating the basal stress from boundary conditions imposed at the ice surface yields a boundary-value problem that is ill-posed and unstable, causing surface errors to increase exponentially as depth increases.

In our study we have described an approach to estimating ice thickness that is based on simplified glacier physics and on mass balance accounting applied to automatically delineated glacier flowsheds. By framing the question as a geophysical inversion problem, smoothness can be controlled using a space-varying tradeoff parameter rather than applied separately at some later stage. The method performs best when glaciers are near equilibrium with a steady 
climate. Tests on synthetically-generated ice cover indicate a tendency for ice thickness to be overestimated when climate is varying, irrespective of whether this leads to glacier growth or to shrinkage. Applying the method to the mountain glaciers of the Canadian Cordillera yields a DEM of the subglacial topography and new estimates of ice volume for this region. Our best estimate of the ice volume is $2530 \pm 220 \mathrm{~km}^{3}$, equivalent to $6.3 \pm 0.6 \mathrm{~mm}$ of sea-level rise.

We see many areas where future improvements are called for. Accurate DEMs and ice masks are an essential starting point. Development of reliable algorithms for delineating glacier flowsheds should be viewed as a high priority. More challenging will be to remove the reliance on simple stress assumptions and to reframe the question as a nonlinear inverse problem. This will require substantial ingenuity combined with abundant computing resources. Without better knowledge of the mass balance fields this level of complexity is not yet warranted.

\section{Acknowledgments.}

We thank the Canadian Foundation for Climate and Atmospheric Sciences (CFCAS), the Natural Sciences and Engineering Research Council of Canada, BC Hydro, the Columbia Basin Trust, and the Universities of British Columbia and Northern British Columbia for financial support. Simon Ommanney provided references for geophysical measurements of ice thickness in western Canada. This paper is a contribution to the Polar Climate Stability Network and to the Western Canadian Cryospheric Network which were funded by CFCAS and by consortia of Canadian universities. We are grateful to reviewers David Bahr and Daniel Farinotti and to Editor in Chief, Tony Broccoli, for their constructive contributions. 


\section{REFERENCES}

Adalgeirsdóttir, G., G. H. Gudmundsson, and H. Björnsson, 2000: The response of a glacier to a surface disturbance: a case study on Vatnajökull ice cap, Iceland. Ann. Glaciol., 31, 104-110.

Agassiz, L., 1847: Système glaciare. Nouvelles études et expériences sur les glaciers actuels, leur structure, leur progression et leur action physique sur le sol. V. Masson, Paris.

Albrecht, O., P. Jansson, and H. Blatter, 2000: Modelling glacier response to measured mass-balance forcing. Ann. Glaciol., 31, 91-96.

Anonymous, 1992: British Columbia specifications and guidelines for geomatics, release 2.0. Tech. rep., British Columbia Ministry of Environment, Victoria, BC, Canada.

Anslow, F. S., V. Radić, A. H. Jarosch, G. K. C. Clarke, B. Menounos, and E. Schiefer, in preparation: High-resolution simulations of the mass balance of western Canadian glaciers from 1980 to 2008 using the North American Regional Reanalysis. J. Glaciol., xxx, xxx$\mathrm{xxx}$.

Bahr, D. B., 1997: Global distributions of glacier properties: A stochastic scaling paradigm. Water Resour. Res., 102, 1669-1679.

Bahr, D. B., M. F. Meier, and S. D. Peckham, 1997: The physical basis of glacier volume-area scaling. J. Geophys. Res., 102, 20,255-20,362.

Bahr, D. B., W. T. Pfeffer, and M. F. Meier, 1994: Theoretical limitations to englacial velocity calculations. J. Glaciol., 40, 509-518.

Beedle, M., 2006: GLIMS Glacier Database. Digital media, National Snow and Ice Data Center/World Data Center for Glaciology. 
Berthier, E., E. Schiefer, G. K. C. Clarke, B. Menounos, and F. Rémy, 2010: Contribution of Alaskan glaciers to sea-level rise derived from satellite imagery. Nature Geosci., 3, 92-95.

Bolch, T., B. Menounos, and R. Wheate, 2010: Landsat-based inventory of glaciers in western Canada, 1985-2005. Remote Sens. Environ., 114, 127-137.

Chen, J. and A. Ohmura, 1990: Estimation of Alpine glacier water resources and their change since 1870s. IAHS, 193, 127-135.

Clarke, G. K. C., E. Berthier, C. G. Schoof, and A. H. Jarosch, 2009: Neural networks applied to estimating subglacial topography and glacier volume. J. Climate, 22, 2146-2160.

Cuffey, K. M. and W. S. B. Paterson, 2010: The Physics of Glaciers. 4th ed., Elsevier, Oxford.

Doell, R. R., 1963: Seismic depth study of the Salmon Glacier, British Columbia. J. Glaciol., 4, 425-437.

Fairfield, J. and P. Leymarie, 1991: Drainage networks from grid digital elevation models. Water Resour. Res., 27, 709-717.

Farinotti, D., 2010: Simple methods for inferring glacier-thickness and snow-accumulation distribution. Mitteilungen 215, Versuchsanstalt für Wasserbau, Hydrologie und Glaziologie, Eidgenössische Technische Hochschule.

Farinotti, D., M. Huss, A. Bauder, and M. Funk, 2009b: An estimate of the glacier ice volume in the Swiss Alps. Global Planet. Change, 68, 225-231.

Farinotti, D., M. Huss, A. Bauder, M. Funk, and M. Truffer, 2009a: A method to estimate the ice volume and ice-thickness distribution of alpine glaciers. J. Glaciol., 55, 422-430.

Farr, T. G., et al., 2007: The Shuttle Radar Topography Mission. Rev. Geophys., 45, RG2004, doi:10.1029/2005RG000183. 
Fisher, D. A., N. Reeh, and K. Langley, 1985: Objective reconstructions of the late Wisconsinan Laurentide Ice Sheet and the significance of deformable beds. Géog. Phys. Quat., 39, 229-238.

Fowler, A. C. and D. A. Larson, 1978: On the flow of polythermal glaciers. I. Model and preliminary analysis. Proc. R. Soc. London, 363, 217-242.

Gudmundsson, H., 1999: A three-dimensional numerical model of the confluence area of Unteraargletscher, Bernese Alps, Switzerland. J. Glaciol., 45, 219-230.

Haeberli, W. and M. Hoelzle, 1995: Application of inventory data for estimating characteristics of and regional climate-change effects on mountain glaciers: a pilot study with the European Alps. Ann. Glaciol., 21, 206-212.

Holdsworth, G., M. N. Demuth, and T. M. H. Beck, 2006: Radar measurements of ice thickness on Peyto Glacier - geophysical and climatic implications. Peyto Glacier: One Century of Science, M. N. Demuth, D. S. Munro, and G. J. Young, Eds., National Hydrology Research Institute, Canada, Vol. 8, 59-79.

Hubbard, A., H. Blatter, P. Nienow, D. Mair, and B. Hubbard, 1998: Comparison of a threedimensional model for glacier flow with field data from Haut Glacier d'Arolla, Switzerland. J. Glaciol., 44, 368-378.

Huss, M. and D. Farinotti, 2012: Distributed ice thickness and volume of all glaciers around the globe. J. Geophys. Res., 117, F04010, doi:10.1029/2012JF002523.

Jarosch, A. H., F. S. Anslow, and G. K. C. Clarke, 2012a: High-resolution precipitation and temperature downscaling for glacier models. Clim. Dyn., 38, 391-409.

Jarosch, A. H., C. G. Schoof, and F. S. Anslow, 2012b: Numerical mass conservation issues in shallow ice models of mountain glaciers: the use of flux limiters and a benchmark. Cryosphere Discuss., 6, 4037-4070, doi:10.5194/tcd-6-4037-2012. 
Kanasewich, E. R., 1963: Gravity measurements on the Athabasca Glacier, Alberta, Canada. J. Glaciol., 4, 617-631.

Kaser, G., M. Großhauser, and B. Marzeion, 2010: Contribution potential of glaciers to water availability in different climate regimes. Proc. Nat. Acad. Sci., 107, 20 223-20227.

Lemke, P., et al., 2007: Observations: Changes in snow, ice and frozen ground. Climate Change 200\%: The Physical Basis. Contribution of Working Group I to the Fourth Assessment Report of the Intergovernmental Panel on Climate Change, S. Solomon, D. Qin, M. Manning, Z. Chen, M. Marquis, K. B. Averyt, M. Tignor, and H. L. Miller, Eds., Cambridge University Press, Cambridge, 337-383.

Li, H., Z. Li, M. Zhang, and W. Li, 2011: An improved method based on shallow ice approximation to calculate ice thickness along flow-line and volume of mountain glaciers. J. Earth Sci., 22, 441-448.

Linsbauer, A., F. Paul, and W. Haeberli, 2012: Modeling glacier thickness distribution and bed topography over entire mountain ranges with GlabTop: Application of a fast and robust approach. J. Geophys. Res., 117, F03007, doi:10.1029/2011JF002313.

Linsbauer, A., F. Paul, M. Hoelzle, H. Frey, and W. Haeberli, 2009: The Swiss Alps without glaciers - A GIS-based modelling approach for reconstruction of glacier beds. Proc. of Geomorphometry 2009, Zürich, geomorphometry.org, 243-247.

Marks, D., J. Dozier, and J. Frew, 1984: Automated basin delineation from digital elevation data. Geo-Processing, 2, 299-311.

Marshall, S. J., E. C. White, M. N. Demuth, T. Bolch, R. Wheate, B. Menounos, M. J. Beedle, and J. M. Shea, 2011: Glacier water resources on the eastern slopes of the Canadian Rocky Mountains. Can. Water Resour. J., 36, 109-134. 
Mathews, W. H., 1959: Vertical distribution of velocity in Salmon Glacier, British Columbia. J. Glaciol., 3, 448-454.

Mesinger, F., et al., 2006: North American Regional Reanalysis. Bull. Amer. Meteor. Soc., 87, 343-360.

Meyer, F., 1994: Topographic distance and watershed lines. Signal Processing, 38, 113-125.

Morlighem, M., E. Rignot, H. Seroussi, E. Larour, H. B. Dhia, and D. Aubry, 2011: A mass conservation approach for mapping glacier ice thickness. Geophys. Res. Lett., 38, L19503, doi:10.1029/2011GL048659.

Nye, J. F., 1952a: A method of calculating the thicknesses of the ice-sheets. Nature, 529-530.

Nye, J. F., 1952b: A comparison between the theoretical and measured long profile of the Unteraar Glacier. J. Glaciol., 2, 103-107.

Nye, J. F., 1964: The flow of a glacier in a channel of rectangular, elliptic or parabolic cross-section. J. Glaciol., 5, 661-690.

Orowan, E., 1949: Remarks at joint meeting of the British Glaciological Society, the British Rheologists Club and the Institute of Metals. J. Glaciol., 1, 231-236.

Paterson, W. S. B., 1962: Observations on Athabaska Glacier and their relation to the theory of glacier flow. Ph.D. thesis, University of British Columbia, 158 pp.

Paterson, W. S. B., 1970: The sliding velocity of Athabasca Glacier, Canada. J. Glaciol., 9, $55-63$.

Paul, F. and A. Linsbauer, 2011: Modeling of glacier bed topography from glacier outlines, central branch lines, and a DEM. Int. J. Geogr. Inform. Sci., doi:10.1080/13658816.2011. 627859. 
Press, W. H., S. A. Teukolsky, W. T. Vetterling, and B. P. Flannery, 2007: Numerical Recipes. 3d ed., Cambridge University Press, Cambridge.

Radić, V. and R. Hock, 2010: Regional and global volumes of glaciers derived from statistical upscaling of glacier inventory data. J. Geophys. Res., 115, F01010, doi: 10.1029/2009JF001373.

Radić, V. and R. Hock, 2011: Regionally differentiated contribution of mountain glaciers and ice caps to future sea-level rise. Nature Geosci., 4, 91-94.

Raymond, C. F., 1971a: Determination of the three-dimensional velocity in a glacier. J. Glaciol., 10, 39-53.

Raymond, C. F., 1971b: Flow in a transverse section of Athabasca Glacier, Alberta, Canada. J. Glaciol., 10, 55-84.

Reeh, N., 1982: A plasticity theory approach to the steady-state shape of a three-dimensional ice sheet. J. Glaciol., 28, 431-455.

Reeh, N., 1984: Reconstruction of the glacial ice covers of the Greenland and the Canadian Arctic islands by three-dimensional, perfectly plastic ice-sheet modelling. Ann. Glaciol., $5,115-121$.

Russell, R. D., J. A. Jacobs, and F. S. Grant, 1960: Gravity measurements on the Salmon Glacier and adjoining snow field, British Columbia, Canada. Bull. Geol. Soc. Am., 71, $1223-1230$.

Schiefer, E., B. Menounos, and R. Wheate, 2007: Recent volume loss of British Columbian glaciers, Canada. Geophys. Res. Lett., 34, L16503, doi:10.1029/2007GL030780.

Schwanghart, W. and N. J. Kuhn, 2010: TopoToolbox: A set of Matlab functions for topographic analysis. Environ. Model. Software, 25, 770-781. 
${ }_{871}$ Tarboton, D. G., 1997: A new method for the determination of flow directions and upslope 872 areas in grid digital elevation models. Water Resour. Res., 33, 309-319.

${ }_{873}$ Truffer, M., K. A. Echelmeyer, and W. D. Harrison, 2001: Implications of till deformation 874 on glacier dynamics. J. Glaciol., 47, 124-134. 


\section{List of Tables}

1 Input and derived properties of steady-state glacier test models. $\mathrm{d} \dot{b}^{-} / \mathrm{d} z=$ elevation gradient of mass balance rate in the ablation zone; $\mathrm{d} \dot{b}^{+} / \mathrm{d} z=$ elevation gradient of mass balance rate in the accumulation zone; $\alpha_{\mathrm{I}}=$ fractional area of ice cover. 41

2 Summary of estimation errors in performance tests of steady-state models. Model averages are calculated for ice-covered cells and not the entire map.

3 Summary of estimation errors in performance tests of transient models having temporally decreasing ice-cover. Model averages are calculated for ice-covered cells and not the entire map.

4 Summary of estimation errors in performance tests of transient models having temporally increasing ice-cover. Model averages are calculated for ice-covered cells and not the entire map.

5 Sensitivity of ice volume estimates to changes in mass balance field. From downscaled mass balance rates fields $\dot{b}(x, y, t)$ we construct the time averages $\bar{b}_{1980}^{2008}, \bar{b}_{1980}^{1989}, \bar{b}_{1990}^{1999}$, and $\bar{b}_{1999}^{2008}$ and compare their effect on ice volume estimates. Ocean area is taken as $3.62 \times 10^{8} \mathrm{~km}^{2}$ with $\rho=910 \mathrm{~kg} \mathrm{~m}^{-3}$, and $\rho_{\mathrm{w}}=1000 \mathrm{~kg} \mathrm{~m}^{-3}$.

6 Summary of ice volume estimates for glaciers of western Canada. The $\overline{\dot{b}}_{1980}^{2008}$ mass balance rate fields in combination with three different thinning rate models: $\dot{H}=0$ (no thinning), $\dot{H}=\dot{H}(z)$ (elevation-dependent thinning), and $\dot{H}=\dot{H}(x, y)$ (spatially-varying thinning). Ocean area is taken as $3.62 \times 10^{8} \mathrm{~km}^{2}$ with $\rho=910 \mathrm{~kg} \mathrm{~m}^{-3}$, and $\rho_{\mathrm{w}}=1000 \mathrm{~kg} \mathrm{~m}^{-3}$. 
$7 \quad$ Summary of sources of error and estimates of error magnitude. Ocean area is taken as $3.62 \times 10^{8} \mathrm{~km}^{2}$ with $\rho=910 \mathrm{~kg} \mathrm{~m}^{-3}$, and $\rho_{\mathrm{w}}=1000 \mathrm{~kg} \mathrm{~m}^{-3}$. Thus $1 \mathrm{~km}^{3}$ ice volume corresponds to $2.51 \mu \mathrm{m}$ of sea-level rise and $1 \mathrm{~mm}$ SLE corresponds to $398 \mathrm{~km}^{3}$ ice volume. For the error estimates the total area of ice cover is taken as $26586 \mathrm{~km}^{2}$ (the 2005 value from Table 6) and the total ice volume as $5.8 \mathrm{~mm}$ SLE (from Table 5). 
TABLE 1. Input and derived properties of steady-state glacier test models. $\mathrm{d} \dot{b}^{-} / \mathrm{d} z=$ elevation gradient of mass balance rate in the ablation zone; $\mathrm{d} \dot{b}^{+} / \mathrm{d} z=$ elevation gradient of mass balance rate in the accumulation zone; $\alpha_{\mathrm{I}}=$ fractional area of ice cover.

\begin{tabular}{lccccc} 
Model name & $\begin{array}{c}\text { ELA } \\
(\mathrm{m})\end{array}$ & $\begin{array}{c}\mathrm{d} \dot{b}^{-} / \mathrm{d} z \\
\left(\mathrm{yr}^{-1}\right)\end{array}$ & $\begin{array}{c}\mathrm{d}^{+} / \mathrm{d} z \\
\left(\mathrm{yr}^{-1}\right)\end{array}$ & $\begin{array}{c}\alpha_{\mathrm{I}} \\
(\%)\end{array}$ & $\begin{array}{c}\text { Ice volume } \\
\left(\mathrm{km}^{3}\right)\end{array}$ \\
\hline \hline BC1·1550L & 1550 & 0.0002 & 0.0001 & 8.77 & 20.11 \\
BC1·1600L & 1600 & 0.0002 & 0.0001 & 4.92 & 9.58 \\
BC1·1650L & 1650 & 0.0002 & 0.0001 & 2.50 & 3.82 \\
BC1·1700L & 1700 & 0.0002 & 0.0001 & 1.07 & 1.34 \\
BC1·1550H & 1550 & 0.0020 & 0.0010 & 13.37 & 71.82 \\
BC1·1600H & 1600 & 0.0020 & 0.0010 & 6.24 & 23.28 \\
BC1·1650H & 1650 & 0.0020 & 0.0010 & 3.11 & 9.13 \\
BC1·1700H & 1700 & 0.0020 & 0.0010 & 1.25 & 2.77 \\
BC1 average & - & - & - & 5.15 & 17.73 \\
\hline BC2·1650L & 1650 & 0.0002 & 0.0001 & 25.86 & 56.96 \\
BC2·1700L & 1700 & 0.0002 & 0.0001 & 18.07 & 28.06 \\
BC2·1800L & 1800 & 0.0002 & 0.0001 & 7.78 & 8.15 \\
BC2·1900L & 1900 & 0.0002 & 0.0001 & 2.60 & 2.26 \\
BC2·1650H & 1650 & 0.0020 & 0.0010 & 31.00 & 331.16 \\
BC2·1700H & 1700 & 0.0020 & 0.0010 & 22.17 & 97.71 \\
BC2·1800H & 1800 & 0.0020 & 0.0010 & 8.44 & 15.63 \\
BC2·1900H & 1900 & 0.0020 & 0.0010 & 2.74 & 3.84 \\
BC2 average & - & - & - & 14.83 & 67.97 \\
\hline BC3·1650L & 1650 & 0.0002 & 0.0001 & 19.22 & 39.77 \\
BC3·1700L & 1700 & 0.0002 & 0.0001 & 13.05 & 21.14 \\
BC3·1800L & 1800 & 0.0002 & 0.0001 & 5.00 & 5.51 \\
BC3·1850L & 1850 & 0.0002 & 0.0001 & 2.75 & 2.74 \\
BC3·1650H & 1650 & 0.0020 & 0.0010 & 37.85 & 407.53 \\
BC3·1700H & 1700 & 0.0020 & 0.0010 & 15.26 & 53.68 \\
BC3·1800H & 1800 & 0.0020 & 0.0010 & 5.57 & 10.72 \\
BC3·1850H & 1850 & 0.0020 & 0.0010 & 2.96 & 4.80 \\
BC3 average & - & - & - & 12.71 & 68.24 \\
\hline YT1·1650L & 1650 & 0.0002 & 0.0001 & 19.01 & 31.35 \\
YT1·1700L & 1700 & 0.0002 & 0.0001 & 12.26 & 17.68 \\
YT1·1800L & 1800 & 0.0002 & 0.0001 & 4.25 & 4.98 \\
YT1·1900L & 1900 & 0.0002 & 0.0001 & 1.06 & 0.99 \\
YT1·1650H & 1650 & 0.0020 & 0.0010 & 22.03 & 72.03 \\
YT1·1700H & 1700 & 0.0020 & 0.0010 & 13.78 & 34.80 \\
YT1·1800H & 1800 & 0.0020 & 0.0010 & 4.65 & 9.05 \\
YT1·1900H & 1900 & 0.0020 & 0.0010 & 1.12 & 1.68 \\
YT1 average & - & - & - & 9.77 & 21.57 \\
\hline & & & & &
\end{tabular}


TABLE 2. Summary of estimation errors in performance tests of steady-state models. Model averages are calculated for ice-covered cells and not the entire map.

\begin{tabular}{|c|c|c|c|c|c|c|}
\hline Model name & $\begin{array}{c}\text { Ice } \\
\text { volume } \\
\left(\mathrm{km}^{3}\right)\end{array}$ & $\begin{array}{c}\text { Mean } \\
\text { thickness } \\
\left\langle H_{i, j}\right\rangle \\
(\mathrm{m})\end{array}$ & $\begin{array}{c}\text { Correlation } \\
\text { coefficient } \\
r\end{array}$ & $\begin{array}{l}\text { Mean error } \\
\begin{array}{c}\left\langle\widetilde{H}_{i, j}-H_{i, j}\right\rangle \\
(\mathrm{m})\end{array}\end{array}$ & $\begin{array}{c}\sigma \\
(\mathrm{m})\end{array}$ & $\begin{array}{c}\text { Volume error } \\
\qquad \begin{array}{c}(\widetilde{V}-V) / V \\
(\%)\end{array}\end{array}$ \\
\hline $\mathrm{BC} 1 \cdot 1550 \mathrm{~L}$ & 20.11 & 46.79 & 0.8930 & 1.54 & 16.65 & 3.30 \\
\hline BC1·1600L & 9.58 & 39.68 & 0.8830 & -0.36 & 14.13 & -0.90 \\
\hline $\mathrm{BC} 1 \cdot 1650 \mathrm{~L}$ & 3.82 & 31.18 & 0.8050 & -2.14 & 11.43 & -6.88 \\
\hline BC1·1700L & 1.34 & 25.72 & 0.6176 & -3.95 & 10.67 & -15.37 \\
\hline $\mathrm{BC} 1 \cdot 1550 \mathrm{H}$ & 71.82 & 109.61 & 0.9347 & -0.35 & 24.90 & -0.32 \\
\hline $\mathrm{BC} 1 \cdot 1600 \mathrm{H}$ & 23.28 & 76.15 & 0.9070 & 0.92 & 24.18 & 1.20 \\
\hline $\mathrm{BC} 1 \cdot 1650 \mathrm{H}$ & 9.13 & 59.87 & 0.8702 & -1.02 & 19.99 & -1.70 \\
\hline $\mathrm{BC} 1 \cdot 1700 \mathrm{H}$ & 2.77 & 45.26 & 0.7781 & -4.35 & 16.36 & -9.61 \\
\hline $\mathrm{BC} 2 \cdot 1650 \mathrm{~L}$ & 56.96 & 44.95 & 0.9134 & 8.94 & 27.62 & 19.89 \\
\hline $\mathrm{BC} 2 \cdot 1700 \mathrm{~L}$ & 28.06 & 31.69 & 0.8676 & 2.19 & 16.56 & 6.92 \\
\hline $\mathrm{BC} 2 \cdot 1800 \mathrm{~L}$ & 8.15 & 21.36 & 0.6569 & -1.49 & 11.35 & -7.00 \\
\hline BC2·1900L & 2.26 & 17.69 & 0.2438 & -3.88 & 8.99 & -21.95 \\
\hline $\mathrm{BC} 2 \cdot 1650 \mathrm{H}$ & 331.16 & 218.01 & 0.8525 & -61.72 & 104.62 & -28.31 \\
\hline $\mathrm{BC} 2 \cdot 1700 \mathrm{H}$ & 97.71 & 89.94 & 0.9194 & 19.70 & 51.03 & 21.90 \\
\hline $\mathrm{BC} 2 \cdot 1800 \mathrm{H}$ & 15.63 & 37.78 & 0.8181 & -0.38 & 18.68 & -1.01 \\
\hline $\mathrm{BC} 2 \cdot 1900 \mathrm{H}$ & 3.84 & 28.61 & 0.3936 & -5.74 & 13.59 & -20.05 \\
\hline BC3.1650L & 39.77 & 42.22 & 0.9152 & 5.34 & 20.81 & 12.66 \\
\hline BC3.1700L & 21.14 & 33.06 & 0.8698 & 2.28 & 17.05 & 6.90 \\
\hline BC3.1800L & 5.51 & 22.50 & 0.5390 & -3.15 & 10.62 & -13.99 \\
\hline BC3.1850L & 2.74 & 20.28 & 0.3451 & -3.96 & 9.89 & -19.55 \\
\hline BC3.1650H & 407.53 & 219.75 & 0.8300 & 5.60 & 92.31 & 2.55 \\
\hline $\mathrm{BC} 3 \cdot 1700 \mathrm{H}$ & 53.68 & 71.76 & 0.9346 & 12.16 & 36.02 & 16.95 \\
\hline BC3.1800H & 10.72 & 39.24 & 0.7350 & -3.49 & 16.75 & -8.90 \\
\hline $\mathrm{BC} 3 \cdot 1850 \mathrm{H}$ & 4.80 & 33.14 & 0.4364 & -6.11 & 14.39 & -18.43 \\
\hline YT1·1650L & 31.35 & 33.65 & 0.8067 & 2.41 & 16.37 & 7.16 \\
\hline YT1·1700L & 17.68 & 29.44 & 0.7590 & 0.25 & 14.25 & 0.85 \\
\hline YT1·1800L & 4.98 & 23.92 & 0.6058 & -1.91 & 11.60 & -7.97 \\
\hline YT1·1900L & 0.99 & 19.09 & 0.2842 & -3.73 & 8.71 & -19.54 \\
\hline YT1.1650H & 72.03 & 66.73 & 0.9005 & 8.25 & 28.84 & 12.36 \\
\hline YT1.1700H & 34.80 & 51.55 & 0.8256 & 2.27 & 23.29 & 4.40 \\
\hline YT1·1800H & 9.05 & 39.72 & 0.7114 & -2.36 & 17.49 & -5.94 \\
\hline YT1.1900H & 1.68 & 30.62 & 0.3508 & -5.97 & 13.01 & -19.49 \\
\hline Ensemble mean & 43.83 & 53.16 & 0.7251 & -1.38 & 23.19 & -3.43 \\
\hline Ensemble median & 13.15 & 38.51 & 0.8124 & -0.70 & 16.60 & -1.35 \\
\hline
\end{tabular}


TABLE 3. Summary of estimation errors in performance tests of transient models having temporally decreasing ice-cover. Model averages are calculated for ice-covered cells and not the entire map.

\begin{tabular}{|c|c|c|c|c|c|c|}
\hline Model name & $\begin{array}{c}\text { Ice } \\
\text { volume }\end{array}$ & $\begin{array}{c}\text { Mean } \\
\text { thickness } \\
\left\langle H_{i, j}\right\rangle \\
(\mathrm{m})\end{array}$ & $\begin{array}{c}\text { Correlation } \\
\text { coefficient } \\
r\end{array}$ & $\begin{array}{l}\text { Mean error } \\
\begin{array}{c}\left\langle\widetilde{H}_{i, j}-H_{i, j}\right\rangle \\
(\mathrm{m})\end{array}\end{array}$ & $\begin{array}{c}\sigma \\
(\mathrm{m})\end{array}$ & $\begin{array}{c}\text { Volume error } \\
\qquad \begin{array}{c}(\widetilde{V}-V) / V \\
(\%)\end{array}\end{array}$ \\
\hline BC1·1550土100L $\downarrow$ & 17.36 & 36.26 & 0.8853 & 5.54 & 17.11 & 15.29 \\
\hline $\mathrm{BC} 1 \cdot 1600 \pm 100 \mathrm{~L} \downarrow$ & 7.92 & 32.08 & 0.8887 & 2.33 & 13.08 & 7.25 \\
\hline $\mathrm{BC} 1 \cdot 1650 \pm 100 \mathrm{~L} \downarrow$ & 2.93 & 22.53 & 0.8383 & 1.07 & 10.25 & 4.76 \\
\hline $\mathrm{BC} 1 \cdot 1700 \pm 100 \mathrm{~L} \downarrow$ & 0.99 & 15.82 & 0.7355 & 1.74 & 9.49 & 10.98 \\
\hline $\mathrm{BC} 1 \cdot 1550 \pm 100 \mathrm{H} \downarrow$ & 42.47 & 78.14 & 0.9307 & 6.20 & 24.45 & 7.94 \\
\hline $\mathrm{BC} 1 \cdot 1600 \pm 100 \mathrm{H} \downarrow$ & 13.57 & 55.82 & 0.9060 & 7.74 & 23.26 & 13.86 \\
\hline $\mathrm{BC} 1 \cdot 1650 \pm 100 \mathrm{H} \downarrow$ & 3.47 & 35.03 & 0.8560 & 3.11 & 15.75 & 8.87 \\
\hline $\mathrm{BC} 1 \cdot 1700 \pm 100 \mathrm{H} \downarrow$ & 0.86 & 22.18 & 0.8120 & 3.67 & 12.15 & 16.54 \\
\hline$\overline{\mathrm{BC} 2 \cdot 1650 \pm 100 \mathrm{~L} \downarrow}$ & 50.71 & 39.28 & 0.9168 & 10.32 & 26.85 & 26.27 \\
\hline $\mathrm{BC} 2 \cdot 1700 \pm 100 \mathrm{~L} \downarrow$ & 24.24 & 26.38 & 0.8755 & 4.19 & 15.21 & 15.88 \\
\hline $\mathrm{BC} 2 \cdot 1800 \pm 100 \mathrm{~L} \downarrow$ & 6.61 & 15.83 & 0.7305 & 1.60 & 9.52 & 10.09 \\
\hline $\mathrm{BC} 2 \cdot 1900 \pm 100 \mathrm{~L} \downarrow$ & 1.68 & 10.87 & 0.5713 & 1.46 & 7.38 & 13.42 \\
\hline $\mathrm{BC} 2 \cdot 1650 \pm 100 \mathrm{H} \downarrow$ & 198.64 & 133.17 & 0.8747 & 16.02 & 70.12 & 12.03 \\
\hline $\mathrm{BC} 2 \cdot 1700 \pm 100 \mathrm{H} \downarrow$ & 69.71 & 77.88 & 0.9195 & 12.75 & 41.97 & 16.38 \\
\hline $\mathrm{BC} 2 \cdot 1800 \pm 100 \mathrm{H} \downarrow$ & 17.95 & 30.73 & 0.8734 & 6.32 & 15.35 & 20.57 \\
\hline $\mathrm{BC} 2 \cdot 1900 \pm 100 \mathrm{H} \downarrow$ & 4.44 & 19.78 & 0.6842 & 3.44 & 9.70 & 17.37 \\
\hline$\overline{\mathrm{BC}} 3 \cdot 1650 \pm 100 \mathrm{~L} \downarrow$ & 35.46 & 35.09 & 0.9177 & 8.62 & 21.18 & 24.56 \\
\hline 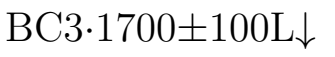 & 18.15 & 27.69 & 0.8674 & 3.98 & 15.64 & 14.39 \\
\hline BC3·1800 $\pm 100 \mathrm{~L} \downarrow$ & 4.40 & 16.51 & 0.6608 & 0.39 & 9.32 & 2.39 \\
\hline 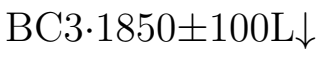 & 0.98 & 11.76 & 0.5801 & 0.48 & 7.76 & 4.04 \\
\hline $\mathrm{BC} 3 \cdot 1650 \pm 100 \mathrm{H} \downarrow$ & 329.59 & 201.23 & 0.8366 & -7.64 & 90.13 & -3.80 \\
\hline $\mathrm{BC} 3 \cdot 1700 \pm 100 \mathrm{H} \downarrow$ & 33.98 & 57.77 & 0.9212 & 12.73 & 33.14 & 22.04 \\
\hline $\mathrm{BC} 3 \cdot 1800 \pm 100 \mathrm{H} \downarrow$ & 11.68 & 29.62 & 0.8035 & 4.54 & 12.38 & 15.31 \\
\hline $\mathrm{BC} 3 \cdot 1850 \pm 100 \mathrm{H} \downarrow$ & 2.73 & 20.96 & 0.6563 & 2.42 & 9.65 & 11.54 \\
\hline YT1·1650土100L $\downarrow$ & 27.27 & 28.41 & 0.8220 & 3.88 & 14.73 & 13.67 \\
\hline $\mathrm{YT} 1 \cdot 1700 \pm 100 \mathrm{~L} \downarrow$ & 14.97 & 23.66 & 0.7501 & 3.10 & 13.87 & 13.09 \\
\hline $\mathrm{YT} 1 \cdot 1800 \pm 100 \mathrm{~L} \downarrow$ & 3.83 & 16.08 & 0.6365 & 3.46 & 11.48 & 21.52 \\
\hline YT1·1900 $\pm 100 L \downarrow$ & 0.77 & 12.77 & 0.5342 & 0.98 & 7.87 & 7.70 \\
\hline $\mathrm{YT} 1 \cdot 1650 \pm 100 \mathrm{H} \downarrow$ & 78.51 & 59.68 & 0.9074 & 13.53 & 28.21 & 22.68 \\
\hline $\mathrm{YT} 1 \cdot 1700 \pm 100 \mathrm{H} \downarrow$ & 38.92 & 43.97 & 0.8599 & 8.68 & 20.67 & 19.75 \\
\hline $\mathrm{YT} 1 \cdot 1800 \pm 100 \mathrm{H} \downarrow$ & 3.86 & 23.15 & 0.7426 & 6.52 & 14.10 & 28.14 \\
\hline $\mathrm{YT} 1 \cdot 1900 \pm 100 \mathrm{H} \downarrow$ & 2.02 & 21.61 & 0.7040 & 3.46 & 9.00 & 16.02 \\
\hline Ensemble mean & 33.41 & 40.05 & 0.7968 & 4.89 & 20.02 & 14.08 \\
\hline Ensemble median & 12.55 & 28.05 & 0.8375 & 3.77 & 14.41 & 14.12 \\
\hline
\end{tabular}


TABLE 4. Summary of estimation errors in performance tests of transient models having temporally increasing ice-cover. Model averages are calculated for ice-covered cells and not the entire map.

\begin{tabular}{|c|c|c|c|c|c|c|}
\hline Model name & $\begin{array}{c}\text { Ice } \\
\text { volume }\end{array}$ & $\begin{array}{c}\text { Mean } \\
\text { thickness } \\
\left\langle H_{i, j}\right\rangle \\
(\mathrm{m})\end{array}$ & $\begin{array}{c}\text { Correlation } \\
\text { coefficient } \\
r\end{array}$ & $\begin{array}{l}\text { Mean error } \\
\begin{array}{c}\left\langle\widetilde{H}_{i, j}-H_{i, j}\right\rangle \\
(\mathrm{m})\end{array}\end{array}$ & $\begin{array}{c}\sigma \\
(\mathrm{m})\end{array}$ & $\begin{array}{c}\text { Volume error } \\
\qquad \begin{array}{c}(\widetilde{V}-V) / V \\
(\%)\end{array}\end{array}$ \\
\hline$\overline{\mathrm{BC} 1 \cdot 1550 \pm 100 \mathrm{~L} \uparrow}$ & 19.05 & 35.47 & 0.8998 & 6.31 & 15.27 & 17.79 \\
\hline $\mathrm{BC} 1 \cdot 1600 \pm 100 \mathrm{~L} \uparrow$ & 8.98 & 27.63 & 0.8790 & 7.07 & 13.69 & 25.58 \\
\hline $\mathrm{BC} 1 \cdot 1650 \pm 100 \mathrm{~L} \uparrow$ & 3.49 & 18.77 & 0.8500 & 6.25 & 10.57 & 33.30 \\
\hline $\mathrm{BC} 1 \cdot 1700 \pm 100 \mathrm{~L} \uparrow$ & 1.23 & 14.88 & 0.7787 & 5.22 & 9.41 & 35.09 \\
\hline $\mathrm{BC} 1 \cdot 1550 \pm 100 \mathrm{H} \uparrow$ & 57.55 & 80.98 & 0.9348 & 7.75 & 24.98 & 9.58 \\
\hline $\mathrm{BC} 1 \cdot 1600 \pm 100 \mathrm{H} \uparrow$ & 22.52 & 55.85 & 0.9112 & 8.70 & 23.21 & 15.58 \\
\hline $\mathrm{BC} 1 \cdot 1650 \pm 100 \mathrm{H} \uparrow$ & 8.24 & 35.46 & 0.8874 & 7.41 & 16.17 & 20.90 \\
\hline $\mathrm{BC} 1 \cdot 1700 \pm 100 \mathrm{H} \uparrow$ & 3.57 & 27.39 & 0.8524 & 6.07 & 12.76 & 22.15 \\
\hline $\mathrm{BC} 2 \cdot 1650 \pm 100 \mathrm{~L} \uparrow$ & 55.78 & 37.79 & 0.9076 & 9.39 & 24.15 & 24.84 \\
\hline $\mathrm{BC} 2 \cdot 1700 \pm 100 \mathrm{~L} \uparrow$ & 27.93 & 25.37 & 0.8703 & 5.83 & 14.35 & 22.99 \\
\hline $\mathrm{BC} 2 \cdot 1800 \pm 100 \mathrm{~L} \uparrow$ & 8.32 & 14.70 & 0.7398 & 4.83 & 10.08 & 32.84 \\
\hline $\mathrm{BC} 2 \cdot 1900 \pm 100 \mathrm{~L} \uparrow$ & 2.36 & 10.08 & 0.6581 & 4.94 & 7.62 & 48.95 \\
\hline $\mathrm{BC} 2 \cdot 1650 \pm 100 \mathrm{H} \uparrow$ & 247.99 & 130.30 & 0.9225 & 2.91 & 53.79 & 2.23 \\
\hline $\mathrm{BC} 2 \cdot 1700 \pm 100 \mathrm{H} \uparrow$ & 104.98 & 76.58 & 0.9313 & 15.46 & 39.55 & 20.18 \\
\hline $\mathrm{BC} 2 \cdot 1800 \pm 100 \mathrm{H} \uparrow$ & 18.67 & 28.08 & 0.8210 & 6.10 & 15.04 & 21.72 \\
\hline $\mathrm{BC} 2 \cdot 1900 \pm 100 \mathrm{H} \uparrow$ & 6.60 & 21.33 & 0.7012 & 4.73 & 11.92 & 22.17 \\
\hline $\mathrm{BC} 3 \cdot 1650 \pm 100 \mathrm{~L} \uparrow$ & 39.21 & 35.66 & 0.9164 & 8.29 & 18.51 & 23.25 \\
\hline BC3.1700土100L $\uparrow$ & 20.99 & 26.53 & 0.8623 & 6.57 & 15.23 & 24.78 \\
\hline BC3.1800土100L $\uparrow$ & 5.50 & 14.48 & 0.6264 & 5.04 & 10.99 & 34.83 \\
\hline $\mathrm{BC} 3 \cdot 1850 \pm 100 \mathrm{~L} \uparrow$ & 1.35 & 10.61 & 0.6722 & 4.45 & 7.86 & 41.96 \\
\hline $\mathrm{BC} 3 \cdot 1650 \pm 100 \mathrm{H} \uparrow$ & 391.95 & 199.43 & 0.8863 & 8.61 & 78.38 & 4.32 \\
\hline $\mathrm{BC} 3 \cdot 1700 \pm 100 \mathrm{H} \uparrow$ & 58.13 & 59.27 & 0.9349 & 10.99 & 27.09 & 18.55 \\
\hline $\mathrm{BC} 3 \cdot 1800 \pm 100 \mathrm{H} \uparrow$ & 11.68 & 26.46 & 0.7487 & 5.98 & 14.43 & 22.59 \\
\hline $\mathrm{BC} 3 \cdot 1850 \pm 100 \mathrm{H} \uparrow$ & 3.72 & 20.13 & 0.7012 & 4.63 & 11.71 & 23.00 \\
\hline YT1·1650土100L $\uparrow$ & 31.35 & 27.35 & 0.8052 & 7.51 & 15.65 & 27.47 \\
\hline $\mathrm{YT} 1 \cdot 1700 \pm 100 \mathrm{~L} \uparrow$ & 17.72 & 22.79 & 0.7444 & 7.15 & 14.77 & 31.37 \\
\hline $\mathrm{YT} 1 \cdot 1800 \pm 100 \mathrm{~L} \uparrow$ & 4.85 & 14.31 & 0.6825 & 7.77 & 11.48 & 54.35 \\
\hline $\mathrm{YT} 1 \cdot 1900 \pm 100 \mathrm{~L} \uparrow$ & 1.05 & 9.87 & 0.5239 & 6.80 & 9.68 & 68.88 \\
\hline $\mathrm{YT} 1 \cdot 1650 \pm 100 \mathrm{H} \uparrow$ & 77.52 & 55.85 & 0.8988 & 11.49 & 25.66 & 20.57 \\
\hline $\mathrm{YT} 1 \cdot 1700 \pm 100 \mathrm{H} \uparrow$ & 40.86 & 41.23 & 0.8336 & 9.13 & 20.86 & 22.14 \\
\hline $\mathrm{YT} 1 \cdot 1800 \pm 100 \mathrm{H} \uparrow$ & 11.89 & 27.76 & 0.7814 & 7.36 & 16.17 & 26.52 \\
\hline $\mathrm{YT} 1 \cdot 1900 \pm 100 \mathrm{H} \uparrow$ & 2.84 & 18.25 & 0.5329 & 8.28 & 16.40 & 45.38 \\
\hline Ensemble mean & 41.13 & 39.08 & 0.7904 & 7.16 & 19.29 & 27.06 \\
\hline Ensemble median & 14.75 & 27.37 & 0.8337 & 6.94 & 15.13 & 23.12 \\
\hline
\end{tabular}


TABlE 5. Sensitivity of ice volume estimates to changes in mass balance field. From downscaled mass balance rates fields $\dot{b}(x, y, t)$ we construct the time averages $\bar{b}_{1980}^{2008}, \bar{b}_{1980}^{1989}, \bar{b}_{1990}^{1999}$, and $\overline{\dot{b}}_{1999}^{2008}$ and compare their effect on ice volume estimates. Ocean area is taken as $3.62 \times 10^{8} \mathrm{~km}^{2}$ with $\rho=910 \mathrm{~kg} \mathrm{~m}^{-3}$, and $\rho_{\mathrm{w}}=1000 \mathrm{~kg} \mathrm{~m}^{-3}$.

\begin{tabular}{llllll} 
Region name & Code & \multicolumn{4}{c}{ SLE Volume } \\
& ID & $\begin{array}{c}\dot{b}_{1980}^{1989} \\
(\mathrm{~mm})\end{array}$ & $\begin{array}{c}\bar{b}_{1999}^{199} \\
(\mathrm{~mm})\end{array}$ & $\begin{array}{c}\overline{\dot{b}}_{1999}^{2008} \\
(\mathrm{~mm})\end{array}$ & $\begin{array}{c}\overline{\dot{b}}_{1980}^{2008} \\
(\mathrm{~mm})\end{array}$ \\
\hline \hline St. Elias & SE & 0.811 & 0.814 & 0.805 & 0.807 \\
Northern Coast & NC & 2.868 & 2.895 & 2.842 & 2.866 \\
Central Coast & CC & 0.184 & 0.184 & 0.183 & 0.184 \\
Southern Coast & SC & 1.334 & 1.338 & 1.320 & 1.332 \\
Vancouver Island & VI & 0.001 & 0.001 & 0.001 & 0.001 \\
Northern Interior & NI & 0.063 & 0.063 & 0.063 & 0.063 \\
Southern Interior & SI & 0.250 & 0.250 & 0.248 & 0.250 \\
Northern Rockies & NR & 0.053 & 0.053 & 0.052 & 0.053 \\
Central Rockies & CR & 0.064 & 0.064 & 0.064 & 0.064 \\
Southern Rockies & SR & 0.209 & 0.207 & 0.205 & 0.207 \\
Totals & & 5.837 & 5.868 & 5.783 & 5.826 \\
\hline
\end{tabular}


TABLE 6. Summary of ice volume estimates for glaciers of western Canada. The $\overline{\dot{b}}_{1980}^{2008}$ mass balance rate fields in combination with three different thinning rate models: $\dot{H}=0$ (no thinning), $\dot{H}=\dot{H}(z)$ (elevation-dependent thinning), and $\dot{H}=\dot{H}(x, y)$ (spatiallyvarying thinning). Ocean area is taken as $3.62 \times 10^{8} \mathrm{~km}^{2}$ with $\rho=910 \mathrm{~kg} \mathrm{~m}^{-3}$, and $\rho_{\mathrm{w}}=1000 \mathrm{~kg} \mathrm{~m}^{-3}$.

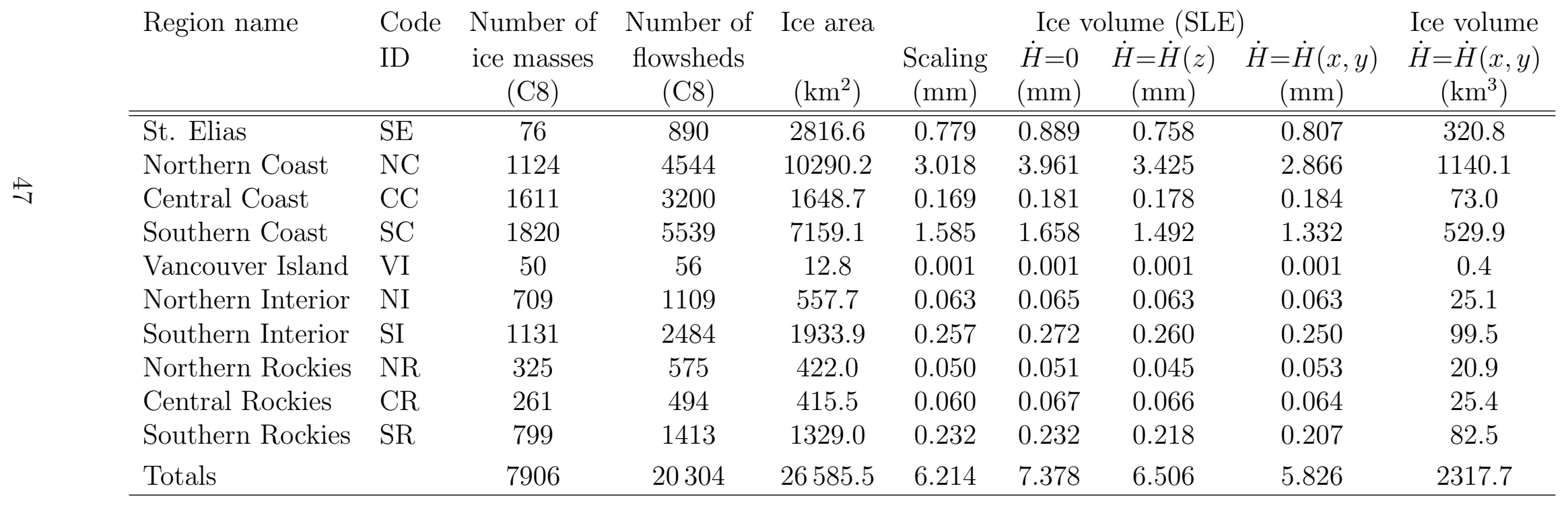


TABLE 7. Summary of sources of error and estimates of error magnitude. Ocean area is taken as $3.62 \times 10^{8} \mathrm{~km}^{2}$ with $\rho=$ $910 \mathrm{~kg} \mathrm{~m}^{-3}$, and $\rho_{\mathrm{w}}=1000 \mathrm{~kg} \mathrm{~m}^{-3}$. Thus $1 \mathrm{~km}^{3}$ ice volume corresponds to $2.51 \mu \mathrm{m}$ of sea-level rise and $1 \mathrm{~mm}$ SLE corresponds to $398 \mathrm{~km}^{3}$ ice volume. For the error estimates the total area of ice cover is taken as $26586 \mathrm{~km}^{2}$ (the 2005 value from Table 6 ) and the total ice volume as $5.8 \mathrm{~mm}$ SLE (from Table 5).

Error source Comments

Potential systematic errors

Ice flow law coefficient, $\mathcal{A}$

Flow partitioning, $\xi$

Shallow ice approximation and shape factor, $f$

Tradeoff parameter, $\chi$

Ice mask, $I_{i, j}$

Random errors

DEM elevation, $S_{i, j}$

Ice mask, $I_{i, j}$

Thinning rate, $\dot{H}_{i, j}$, and mass balance model, $\dot{b}_{i, j}$

Flowshed delineation

Balance adjustment
We assume that the flow law coefficient is $\mathcal{A}=2.4 \pm 0.5 \times 10^{-24} \mathrm{~Pa}^{-3} \mathrm{~s}^{-1}$ and apply Equation 20 to obtain a fractional volume error of $\pm 4.5 \%$.

We assume $\xi=1$ (no sliding), an upper limit on $\xi$ that would overestimate ice volume. Applying Equation 20, the likely volume error is less than 5\%.

We take $f=1$ which is an upper limit. With $f=0.75$ applied universally, thickness estimates would increase the volume by $33 \%$. Overall a $20 \%$ increase cannot be discounted.

$\chi \rightarrow 0$ causes underestimates because of oversmoothing. For $\chi=0.4$ this effect is small. For $\chi \rightarrow 1$ (much larger than desirable) the volume increase is $\sim 0.5 \mathrm{~mm}$.

Total mask areas for $\mathrm{SE}+\mathrm{NC}$ subregions is $2 \%$ less than those of Bolch et al. (2010).

$9 \mathrm{~m}$ absolute error for SRTM elevations in North America (Farr et al., 2007) has no effect. Contribution from random elevation errors should cancel.

Estimated area error from erroneous classification of debris-covered glacier cells as non-ice is $-0.5 \%\left(\delta A^{-}=-154 \mathrm{~km}^{2}\right)$; estimated area error from erroneous classification of snow-covered non-ice cells as ice is $+1.4 \%$ $\left(\delta A^{+}=430 \mathrm{~km}^{2}\right)$. Taking $H^{-}=25 \mathrm{~m}$ and $H^{+}=10 \mathrm{~m}$ gives $\delta V^{-}=-3.8 \mathrm{~km}^{3}$ and $\delta V^{+}=+4.3 \mathrm{~km}^{3}$.

Flowshed balancing removes the effect of bias errors in surface melt and Error range (mm SL Lower Upper accumulation fields. Schieffer et al. (2007) give the thinning rate error as $\pm 0.19 \mathrm{~m} \mathrm{yr}^{-1}$. Random errors of magnitude $\pm 0.2 \mathrm{~m} \mathrm{yr}^{-1}$ give a volume change of $\sim 0.1 \mathrm{~mm}$ when thickness inversion is rerun with these errors added.

Potentially important for individual flowsheds but small cumulative effect.

Not applying flowshed balance adjustment causes $\sim 0.03 \mathrm{~mm}$ volume change $-0.03$ $+0.03$

but we consider this correction necessary. 


\section{List of Figures}

1 Surface elevation digital elevation model (DEM), ice mask and automaticallydelineated glacier flowsheds for study region BC2 synthetic example. (a) Surface topography. (b) Ice mask. (c) Glacier flowsheds (each flowshed is represented by a different colour).

2 Ice masks for synthetic glaciation of test regions. The columns correspond to the "H" forcings for each of the regions in Table 1 starting from the lowest ELA value and ending with the highest. (a1-a4) Region BC1 (centered at $\left.55.4635^{\circ} \mathrm{N}, 124.8151^{\circ} \mathrm{W}\right) .(\mathrm{b} 1-\mathrm{b} 4)$ Region $\mathrm{BC} 2$ (centered at $58.9000^{\circ} \mathrm{N}$, 125.8714 $\left.{ }^{\circ} \mathrm{W}\right)$. (c1-c4) Region BC3 (centered at $\left.59.4545^{\circ} \mathrm{N}, 130.3566^{\circ} \mathrm{W}\right)$. (d1-d4) Region YT1 (centered at $\left.61.6014^{\circ} \mathrm{N}, 133.3684^{\circ} \mathrm{W}\right)$.

3 Ice thickness estimation error for Model YT1.1700H. This is an example of below-average performance of the inversion model rather than a selected example of good performance. (a) Plot of estimated thickness $\widetilde{H}$ against true thickness $H$ generated by a numerical glaciation model. (b) Histogram of ice thickness estimation error. Note that the distribution is somewhat skewed because ice thickness cannot be negative. (c) Distribution functions for true (solid line and open circles) and estimated (dashed line and + signs) ice thickness.

4 Maps of assigned basal stress, estimated ice thickness, thickness error, and subglacial topography for Model YT1·1700H. This is an example of belowaverage performance of the inversion model rather than a selected example of good performance. (a) Assigned basal stress. (b) Estimated ice thickness. (c) Thickness estimation error. (d) Bed surface elevation. 
5 Measured and estimated ice thickness for sites on Athabasca, Peyto, and Salmon Glaciers. Measurements were taken decades previously (ca. 1960 for Athabasca, ca. 1984 for Peyto, and 1956 for Salmon). The estimated thickness is based on elevation data and ice masks from ca. 2005. (a) Results without correction for surface lowering. (b) Results corrected for estimated surface lowering that occurred between the measurement date and the thickness estimation date.

6 Glacierization and sub-regions within western Canadian study area. The labeled arrows indicate the locations of Athabasca (A), Peyto (P), and Salmon (S) glaciers for which there are published measurements of ice thickness. 

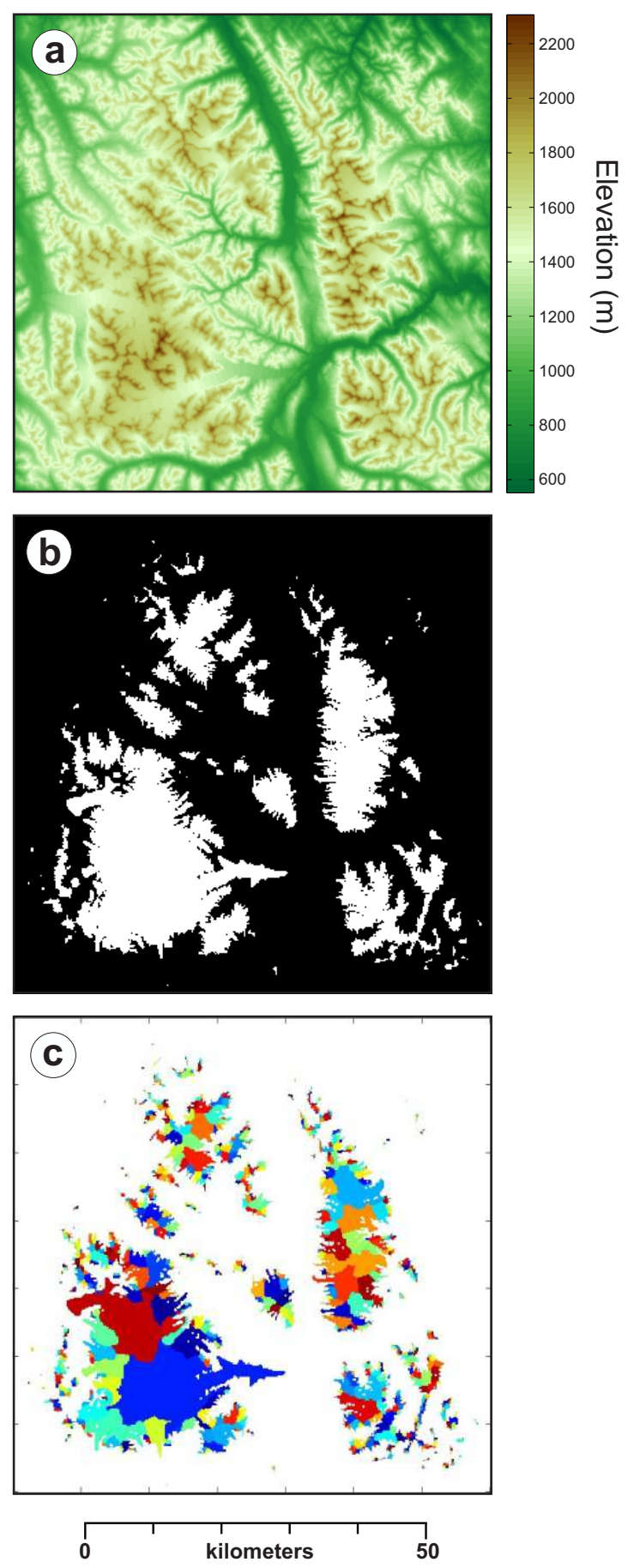

Fig. 1

Clarke et al.

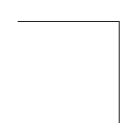

FIG. 1. Surface elevation digital elevation model (DEM), ice mask and automaticallydelineated glacier flowsheds for study region BC2 synthetic example. (a) Surface topography. (b) Ice mask. (c) Glacier flowsheds (each flowshed is represented by a different colour). 
1
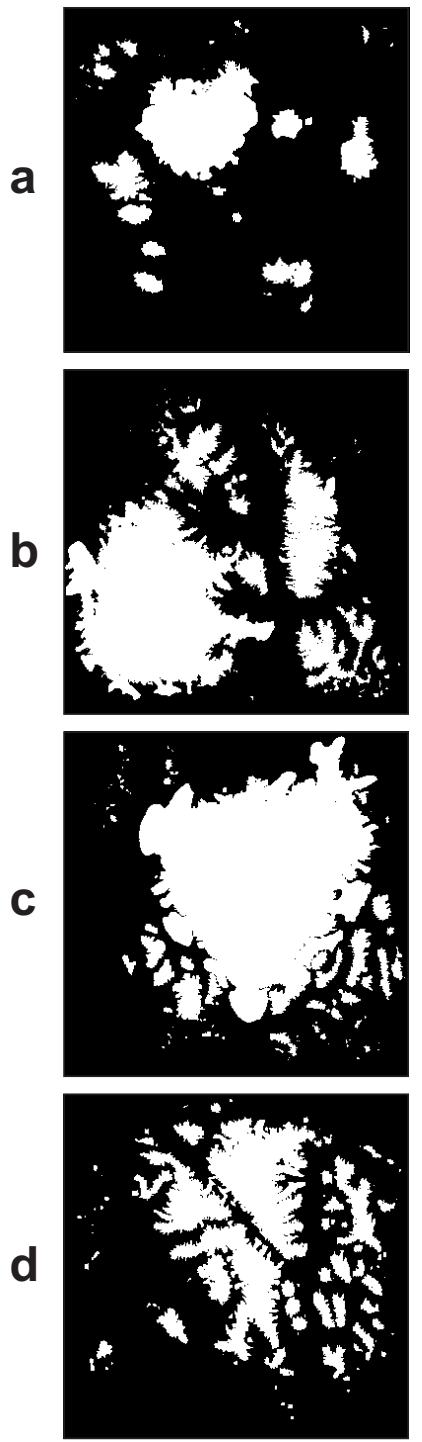

2
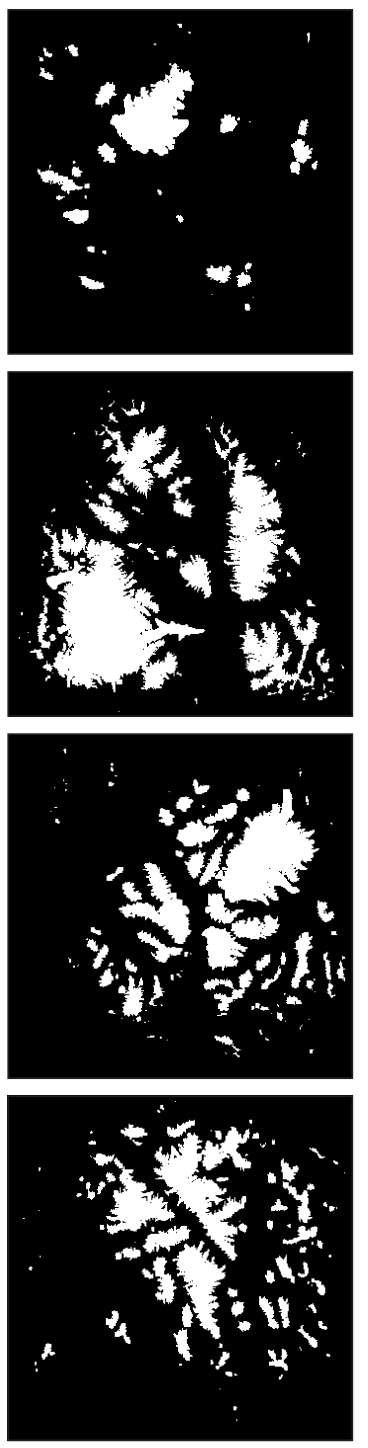

3
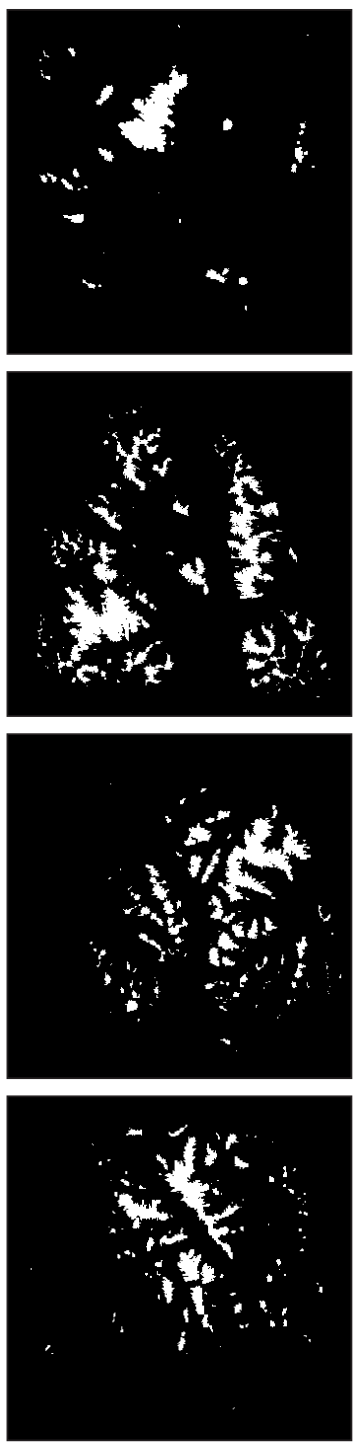

4
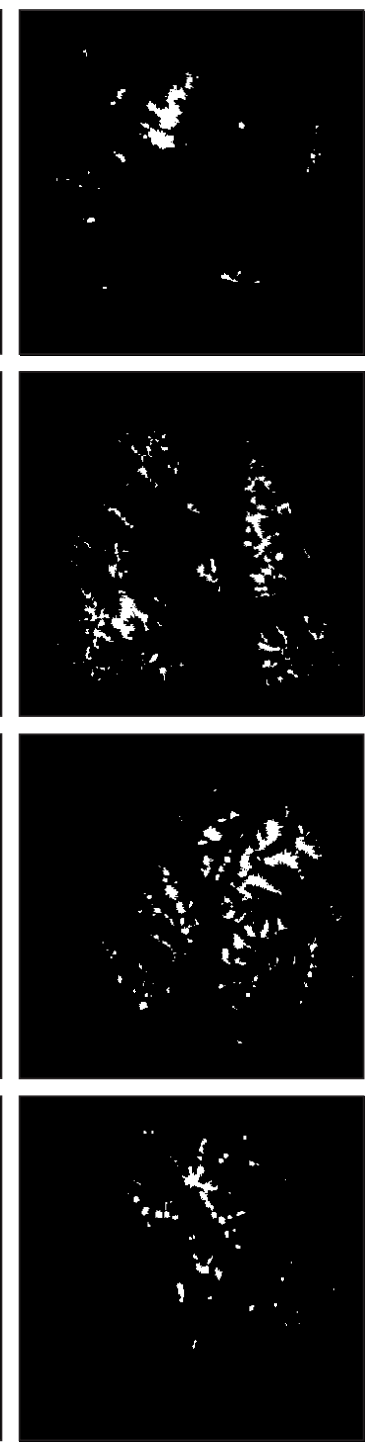

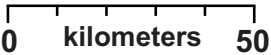

Fig. 2

Clarke et al.

FIG. 2. Ice masks for synthetic glaciation of test regions. The columns correspond to the "H" forcings for each of the regions in Table 1 starting from the lowest ELA value and ending with the highest. (a1-a4) Region BC1 (centered at $55.4635^{\circ} \mathrm{N}, 124.8151^{\circ} \mathrm{W}$ ). (b1b4) Region $\mathrm{BC} 2$ (centered at $58.9000^{\circ} \mathrm{N}, 125.8714^{\circ} \mathrm{W}$ ). (c1-c4) Region $\mathrm{BC} 3$ (centered at $\left.59.4545^{\circ} \mathrm{N}, 130.3566^{\circ} \mathrm{W}\right) .(\mathrm{d} 1-\mathrm{d} 4)$ Region $\mathrm{YT} 1\left(\right.$ centered at $\left.61.6014^{\circ} \mathrm{N}, 133.3684^{\circ} \mathrm{W}\right)$. 

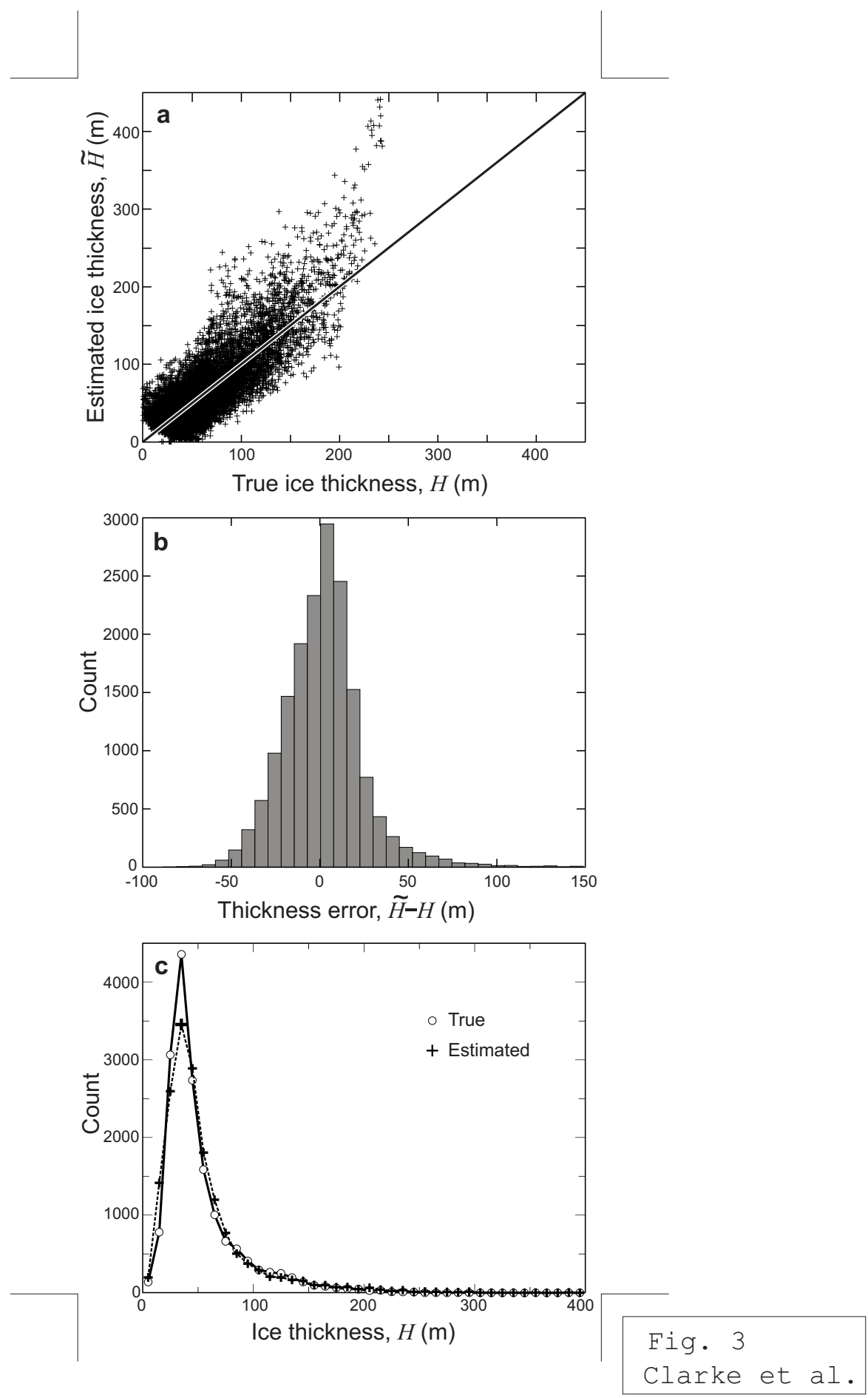

FIG. 3. Ice thickness estimation error for Model YT1.1700H. This is an example of belowaverage performance of the inversion model rather than a selected example of good performance. (a) Plot of estimated thickness $\widetilde{H}$ against true thickness $H$ generated by a numerical glaciation model. (b) Histogram of ice thickness estimation error. Note that the distribution is somewhat skewed because ice thickness cannot be negative. (c) Distribution functions for true (solid line and open circles) and estimated (dashed line and + signs) ice thickness. 

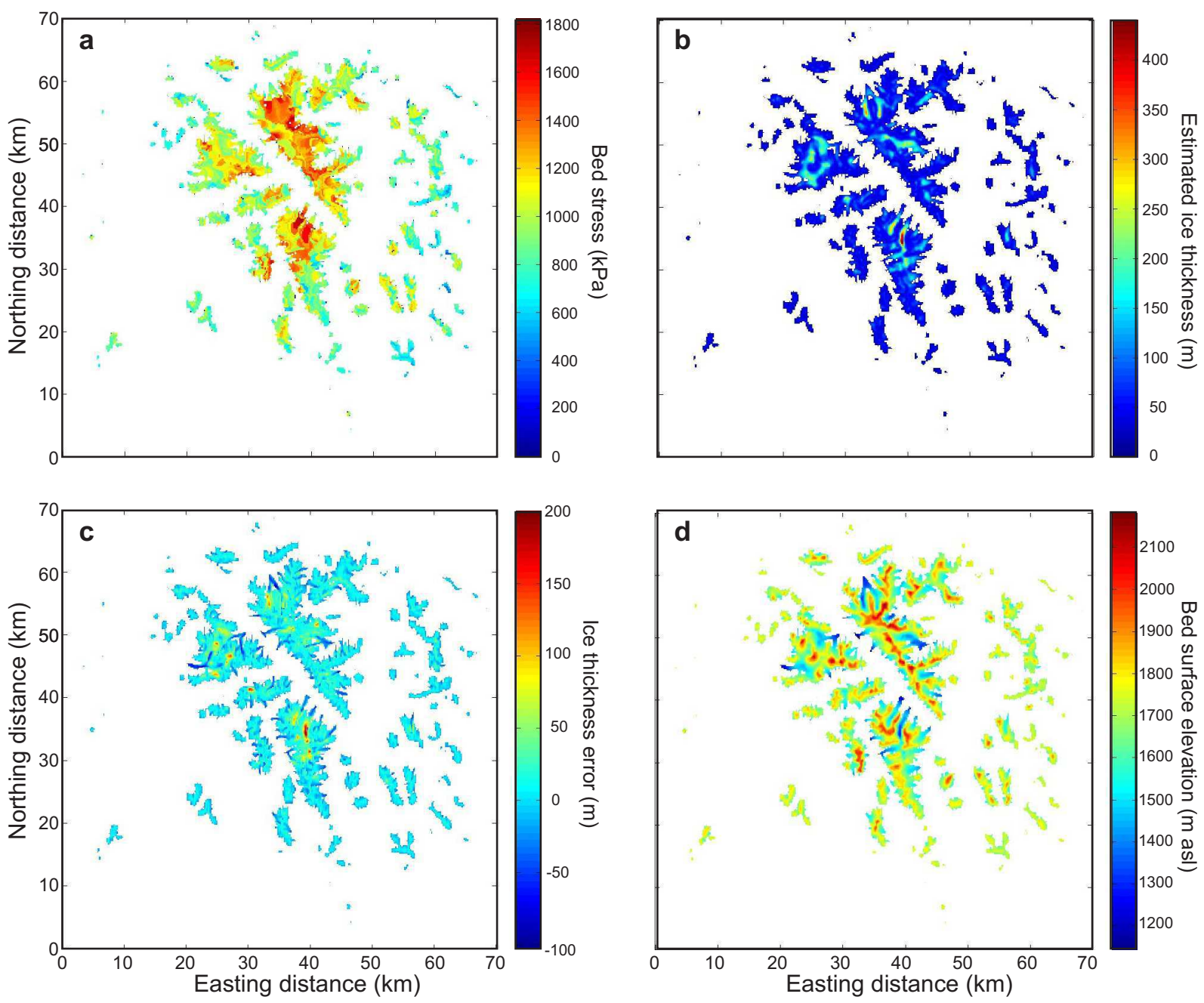

Fig. 4

Clarke et al.

Fig. 4. Maps of assigned basal stress, estimated ice thickness, thickness error, and subglacial topography for Model YT1.1700H. This is an example of below-average performance of the inversion model rather than a selected example of good performance. (a) Assigned basal stress. (b) Estimated ice thickness. (c) Thickness estimation error. (d) Bed surface elevation. 

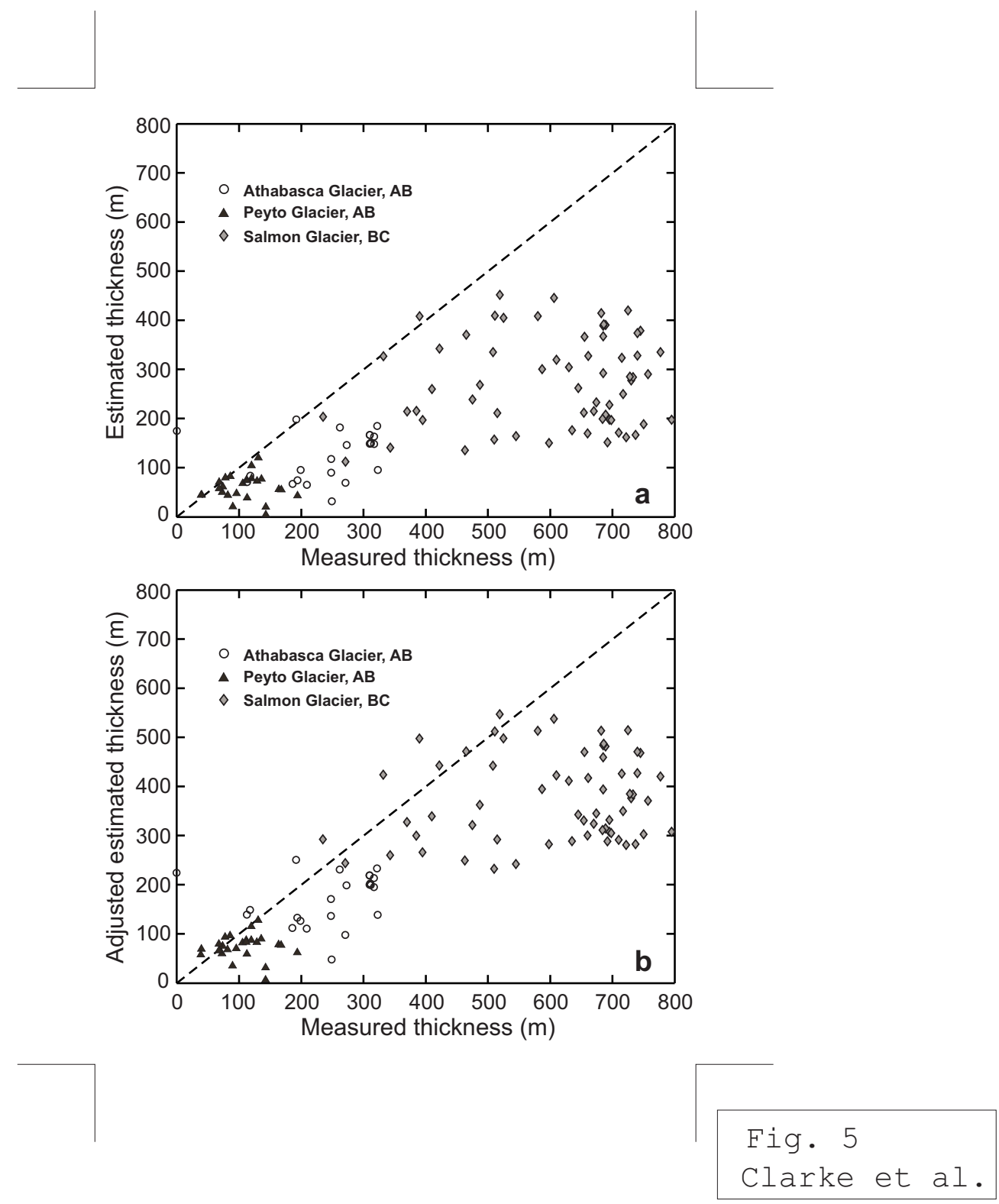

Fig. 5. Measured and estimated ice thickness for sites on Athabasca, Peyto, and Salmon Glaciers. Measurements were taken decades previously (ca. 1960 for Athabasca, ca. 1984 for Peyto, and 1956 for Salmon). The estimated thickness is based on elevation data and ice masks from ca. 2005. (a) Results without correction for surface lowering. (b) Results corrected for estimated surface lowering tha 55 ccurred between the measurement date and the thickness estimation date. 


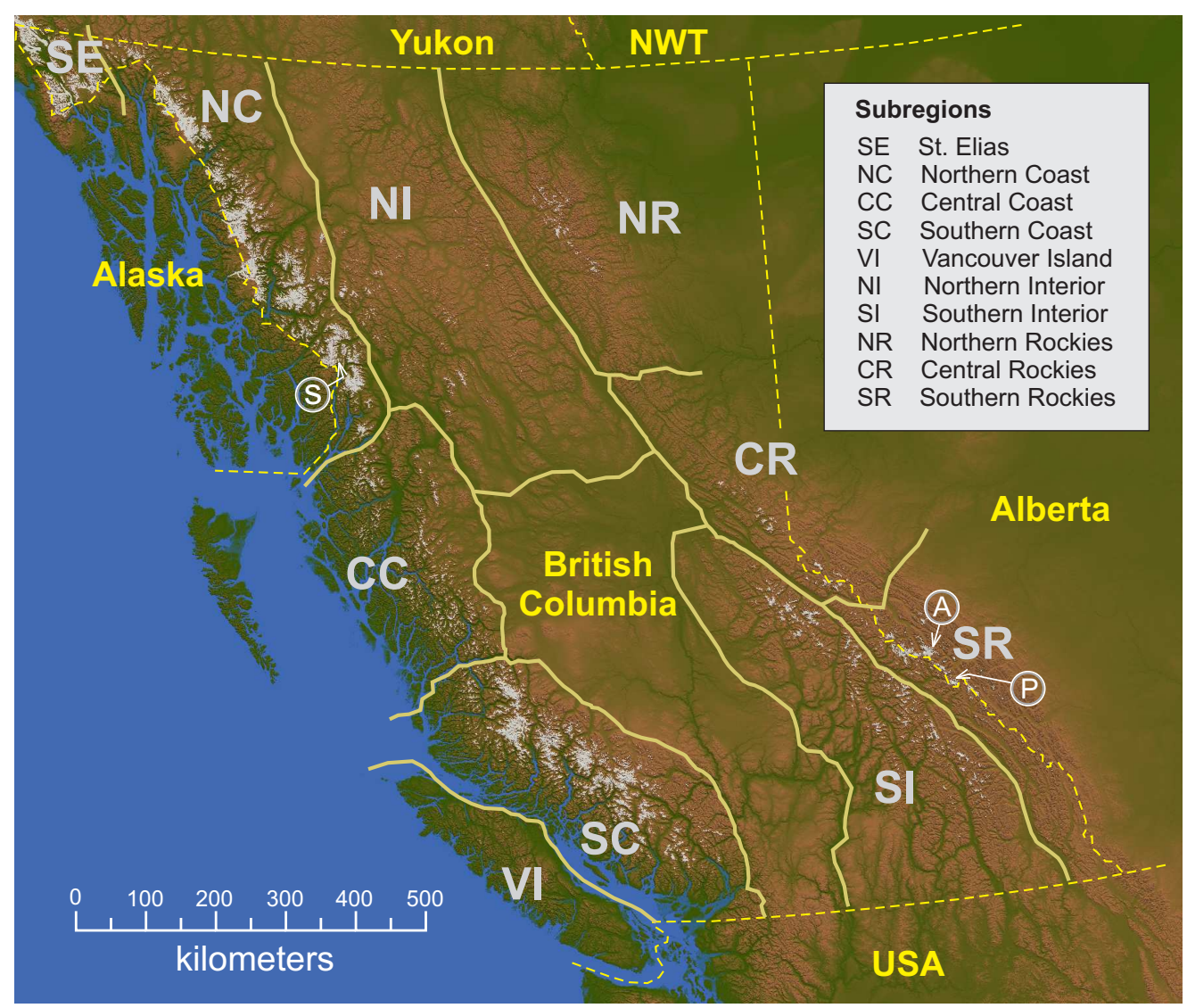

Fig. 6

Clarke et al.

FIG. 6. Glacierization and sub-regions within western Canadian study area. The labeled arrows indicate the locations of Athabasca (A), Peyto (P), and Salmon (S) glaciers for which there are published measurements of ice thickness. 